\title{
The Term Structure of Bond Market Liquidity and Its Implications for Expected Bond Returns
}

\author{
Ruslan Goyenko, Avanidhar Subrahmanyam, and Andrey Ukhov*
}

\begin{abstract}
Previous studies of Treasury market illiquidity span short time periods and focus on particular maturities. In contrast, we study the time series of illiquidity for different maturities over an extended period of time. We also compare time-series determinants of on-therun and off-the-run illiquidity. Illiquidity increases and the difference between spreads of long- and short-term bonds significantly widens during recessions, suggesting a "flight to liquidity," wherein investors shift into the more liquid short-term bonds during economic contractions. Macroeconomic variables such as inflation and federal funds rates forecast off-the-run illiquidity significantly but have only modest forecasting ability for on-the-run illiquidity. Bond returns across maturities are forecastable by off-the-run but not on-therun bond illiquidity. Thus, off-the-run illiquidity, by reflecting macro shocks first, is the primary source of the liquidity premium in the Treasury market.
\end{abstract}

\section{Introduction}

U.S. Treasury markets are crucial for asset allocation purposes as well as in the setting of benchmark riskless rates used by corporations in capital budgeting. Indeed, average daily trading volume in Treasury markets is about $\$ 500$ billion, compared to only about $\$ 100$ billion on the New York Stock Exchange (NYSE). ${ }^{1}$

\footnotetext{
*Goyenko, ruslan.goyenko@mcgill.ca, Desautels Faculty of Management, McGill University, 1001 Sherbrooke St. West, Montreal, Quebec H3A 1G5, Canada; Subrahmanyam, subra@anderson .ucla.edu, Anderson School of Management, University of California at Los Angeles, C4.18 Entrepreneurs Hall, Los Angeles, CA 90095; and Ukhov, andrey.ukhov@gmail.com, School of Hotel Administration, Cornell University, 465C Statler Hall, Ithaca, NY 14853. We are grateful to Avraham Kamara (the referee) for insightful and constructive comments that have greatly improved the paper. We also thank Yakov Amihud, David Bates, Michael Fleming, Tyler Henry, Paul Irvine, Robert Jarrow, Andrei Jirnyi, Paul Kupiec, Paul Malatesta (the editor), Tao Shu, Johannes Skjeltorp, Chris Stivers, Stijn Van Nieuwerburgh, Ginger Wu, and participants in a seminar at the University of Georgia, at the 2007 Conference on Financial Economics and Accounting at New York University, the 18th Annual Derivative Securities and Risk Management Conference at FDIC, the European Finance Association 2008 meeting, and the Center for Research in Security Prices Forum 2008 at University of Chicago Graduate School of Business for valuable comments. Goyenko acknowledges financial support from IFM2. A portion of this research was conducted when Ukhov was visiting Kellogg School of Management, Northwestern University, whose hospitality and collegial environment are gratefully acknowledged.

${ }^{1}$ See http://www.hedgeweek.com/articles/detail.jsp?content_id=238589, quoting a research report by the research firm Celent and the NYSE 2007 Factbook, respectively.
} 
This trading activity allows for price discovery, and Brandt and Kavajecz (2004) argue that the extent of price discovery in the T-bond is intimately linked to the markets' liquidity. Further, events such as the 1998 bond market turmoil have heightened concerns about bond liquidity crises. ${ }^{2}$ Hence, understanding the dynamics of bond market liquidity is of clear academic and practical importance. The attribute of liquidity is also important because it influences expected returns by way of a liquidity premium embedded in bond prices (Amihud, Mendelson, and Pedersen (2005)).

Notwithstanding the importance of understanding liquidity dynamics, there remain critical gaps in the literature on bond market liquidity. ${ }^{3}$ These lacunae arise because the bond market is not homogeneous but its constituent securities vary by maturity and seasonedness (i.e., on-the-run status). For example, while the presence of a liquidity premium in bond prices was first established for off-the-run bonds (Amihud and Mendelson (1991)), the previous literature mostly focuses on the dynamics of on-the-run liquidity. ${ }^{4}$ Thus, off-the-run liquidity dynamics, which are empirically the most relevant for bond pricing, have not yet been studied. Moreover, while the pricing implications of illiquidity in the stock market have been explored in the time series ${ }^{5}$ and on different cross sections of stock portfolios, ${ }^{6}$ the pricing implications of bond liquidity across different maturities are still unexplored in the literature.

We contribute on both the preceding dimensions by making use of a long time series of bond liquidity data. The time span of the analysis is important because it allows us to subsume a variety of economic events. As Shiller and Perron (1985) and Shiller (1989) show, increasing the number of observations by sampling more frequently while leaving the total time span of the data unchanged may not increase the power of tests very much. ${ }^{7}$ We thus consider an extensive time period that spans November 1967-December 2005. For this period,

\footnotetext{
${ }^{2}$ See The Wall Street Journal, "Illiquidity Is Crippling the Bond World" ((Oct. 19, 1998), p. C1), "Illiquidity means it has become more difficult to buy or sell a given amount of any bond but the most popular Treasury issue. The spread between prices at which investors will buy and sell has widened, and the amounts in which Wall Street firms deal have shrunk across the board for investment grade, high-yield (or junk), emerging market and asset-backed bonds.... The sharp reduction in liquidity has preoccupied the Fed because it is the lifeblood of markets" (emphasis added).

${ }^{3}$ Studies on bond liquidity include Amihud and Mendelson (1991), Warga (1992), Boudoukh and Whitelaw (1993), Kamara (1994), Krishnamurthy (2002), Goldreich, Hanke, and Nath (2005), Fleming (2003), Huang, Cai, and Wang (2002), Fleming and Remolona (1999), Balduzzi, Elton, and Green (2001), and Chordia, Sarkar, and Subrahmanyam (2005).

${ }^{4}$ Fleming and Remolona (1997), (1999), Balduzzi et al. (2001), Green (2004), and Chordia et al. (2005).

${ }^{5}$ See Amihud and Mendelson (1986), (1989), Brennan and Subrahmanyam (1996), Amihud (2002), and Jones (2002).

${ }^{6}$ See Amihud (2002), Pastor and Stambaugh (2003), and Acharya and Pedersen (2005).

${ }^{7}$ If two time series make relatively slow movements through time (a common feature for economic data and liquidity series, viz. Jones (2002)), then a long time series (spanning many years) is needed before the true joint tendencies of the two variables can be measured reliably. Shiller (1989) stresses the argument that obtaining many observations by sampling frequently (e.g., through weekly or even daily observations) does not appreciably increase the power to measure the joint relationship between the two time series if the data span a total of only a few years.
} 
we consider the joint dynamics of liquidity and returns across seasonedness (i.e., on- and off-the-run status) and 3 different maturity classes: short, medium, and long.

To our knowledge, no previous study uses such a long time series and describes the dynamics of liquidity and returns across maturities and on-the-run status within a unified framework. We bring together macroeconomic variables, maturity, and liquidity in one study, and this is what separates our paper from the rest of the literature. Our analysis allows us to address the following issues, which are as yet unexamined in the literature:

i) Previous research (Brunnermeier and Pedersen (2009), Chordia, Roll, and Subrahmanyam (2001)) suggests that macroeconomic variables and price volatility may impact bond market liquidity by affecting market-making costs. Do such variables differentially impact on- and off-the-run marketmaking costs and, in turn, liquidities?

ii) How are liquidity shocks transmitted in the bond market? Are they reflected first in the relatively less active off-the-run issues or the more active on-therun issues?

iii) If the liquidity of certain bonds forecasts those of other bonds by reflecting liquidity shocks first, then it may forecast returns not just in the own-market but in other markets as well. This is because liquidity levels in the ownmarket provide information about future liquidity, and liquidity premia in other markets. This leads us to ask: How does the predictive power of liquidity for bond returns vary across maturity and seasonedness?

We find that liquidity conditions in the bond market are significantly affected by the economic environment. For example, bond spreads increase during recessions. Moreover, the difference between spreads of long- and short-term bonds significantly widens during recessions, suggesting that investors shift funds into short-term bonds during this time, thus creating liquidity. This is consistent with flight-to-quality and flight-to-liquidity phenomena.

Our results indicate that short-term liquidity Granger-causes long-term liquidity and that there is very little evidence of reverse Granger causality. This indicates that liquidity shocks are generally transmitted from the short end to the long end. In addition, we find that off-the-run liquidity is predictable by macroeconomic variables. Thus, shocks to inflation and monetary policy tightening, associated with positive shocks to the federal funds rate (FED), affect off-the-run liquidity across maturities, consistent with the notion that these variables affect illiquidity through their effects on real wealth and costs of financing dealer inventory and trading activity. However, for on-the-run liquidity, the predictive power of the macro variables is considerably reduced. This is consistent with the notion that active trading in on-the-run bonds mitigates the impact of macro variables on inventory financing costs.

Our analysis also indicates that positive shocks to bond returns across different maturities decrease off-the-run bond illiquidity, and shocks to volatility increase illiquidity. These results are consistent with those for the stock market described by Chordia et al. (2001), who show that up-market moves have a positive effect on liquidity, and with models of microstructure that argue that increased 
volatility, by increasing inventory risk, tends to increase market illiquidity (Ho and Stoll (1983), O’Hara and Oldfield (1986)).

The liquidity premium has been previously attributed to the yield difference between equivalent instruments but different levels of liquidity. For example, Amihud and Mendelson (1991) find a significant yield differential between T-notes and T-bills with the same time to maturity. Krishnamurthy (2002) studies the price difference between the on-the-run and the most recent off-the-run 30 -year bonds and concludes that the yield difference results from a demand for liquid assets. Longstaff (2004) compares the yield differential between zerocoupon Treasury and Refcorp bonds and also finds evidence of a large liquidity premium. ${ }^{8}$ While these studies add valuable insights, they are limited by the short time spans over which high-frequency market microstructure data are available.

In contrast to previous literature, we look directly at the effect of liquidity on bond returns over the long run in a variety of economic conditions. We use vector autoregression (VAR) analysis, which allows us to account for joint dynamics between liquidity and returns across different maturities. We find that for the overall sample, short-term off-the-run liquidity is priced across all maturities, while medium- and long-term liquidities have no significant impact on prices in a joint dynamic framework. On-the-run liquidity is not priced, either. Consistent with the increasing importance of the long bond in the latter half of the sample period, we find that long bond off-the-run illiquidity is more important in predicting returns than the short bond off-the-run illiquidity. Overall, these results suggest that off-the-run illiquidity, rather than that of the on-the-run issues, is the source of the liquidity premium in the T-bond market.

The rest of the paper is organized as follows. Section II provides the economic arguments that motivate our study. We describe the data and the liquidity measure in Section III. Section IV describes the results of time-series analysis of the illiquidity series, economic variables, and bond returns. Section V presents an analysis for 2 different subperiods representing different illiquidity regimes. Section VI concludes.

\section{Economic Motivation}

This section delineates the questions our data have the opportunity to address. These issues span the behavior of bond liquidity across different states of the macroeconomy, the effect of macroeconomic variables on liquidity, and how the liquidity premium varies across maturities and seasonedness.

First, the behavior of illiquidity during recessions and expansions is of interest. In particular, lower liquidity during recessions due to increased risk premia (Dumas (1994)) can exacerbate market declines as agents demand higher required rates of return (Amihud and Mendelson (1986)). Our data allow an explicit comparison of illiquidity across different macroeconomic regimes and allow us to test

\footnotetext{
${ }^{8}$ See also Warga (1992), Kamara (1994), and Goldreich et al. (2005).
} 
the hypothesis that bond markets are less liquid during recessions than at other times.

It also is often suggested (see, e.g., Brunnermeier and Pedersen (2009)) that tighter collateral constraints during recessions may result in a "flight to liquidity" wherein agents flee to bonds with lower trading costs. This would mean that onthe-run bonds would become even more liquid relative to off-the-run bonds during recessions than in normal times. Our comparison of illiquidity in off-the-run and on-the-run bonds of different maturities during recessions allows an analysis of this issue.

Next, the impact of macroeconomic variables on the bond market across the term structure and seasonedness spectrum is an unexplored issue. Chordia et al. (2005) show that expansionary monetary policy is associated with lower bid-ask spreads in stock and bond markets. Note that the beneficial effect of monetary policy may operate through the demand side (by the actions of traders facing lower financing costs for their trading activities) or the supply side (because of alterations in dealer financing costs). We expect a similar economic effect of monetary policy in our sample. Specifically, we anticipate that decreases in the federal funds rate, indicating a looser monetary policy, would be associated with greater liquidity.

Among other macroeconomic variables, we use inflation, because inflation surprises have a large effect on the level of the entire yield curve (Ang and Piazzesi (2003)). Campbell and Ammer (1993) argue that bond returns are driven largely by news about future inflation. Positive inflation shocks may reduce real wealth and hence drain trading activity out of the bond market, reducing liquidity. Such shocks may also signal a shift in future monetary policy (i.e., the expectation that the Federal Reserve may raise interest rates to dampen inflation) and thus can adversely affect liquidity by portending a shift in inventory financing costs. We would therefore expect positive inflation surprises to have adverse effects on bond market illiquidity.

Fama and French (1993) argue that term and default spreads capture a lot of variation in T-bond returns. Moreover, term and default spreads as proxies for business cycles can be important drivers of illiquidity, since volume injected into the bond market (a driver of illiquidity) may be reduced during downturns due to decreases in aggregate wealth. We therefore include term and default premiums to the vector of state variables. We expect decreases in these variables to increase bond market liquidity and vice versa.

The impact of macro variables may vary by seasonedness. For example, the effect of monetary policy may be more evident in the less-liquid off-the-run issues because that is where dealers have to hold positions for longer periods, on average. Thus, increases in dealer financing costs due to adverse monetary shocks would have a greater adverse effect on off-the-run illiquidity. Further, reductions in trading activity in adverse macroeconomic conditions may increase inventory risk more in off-the-run issues where positions have to be held for longer periods. We would therefore expect macroeconomic variables to have greater impacts on off-the-run liquidity than on-the-run liquidity. Thus, positive shocks to money supply and negative shocks to the federal funds should lead to stronger and more immediate increases in off-the-run rather than in on-the-run liquidity. Similarly, 
positive shocks to inflation, the term premium, or the credit spread should lead to a stronger and more immediate adverse impact on off-the-run illiquidity than on-the-run illiquidity.

There may also be maturity-related effects. For example, if dealer inventory costs are indeed higher in the off-the-run market, they may be more relevant in those maturities with greater order imbalances because that is where inventory would take on more extreme values. It is possible that short-term off-the-run bonds with more volume may also have more extreme order imbalances. On the other hand, an offsetting effect is that long-term bonds have less volume and thus involve a greater time for which dealer positions must be held. This may increase the influence of macro variables on inventory carrying costs and thus, illiquidity in long-term bonds relative to short-term bonds. Thus, the influence of macro information on illiquidity across different maturities is ambiguous, and therefore becomes an empirical issue we are able to address.

Finally, the preceding arguments also have implications for the nature of the liquidity premium in bond prices. For example, if it is indeed the case that offthe-run illiquidity reflects macro information first, then by signaling changes in bond market liquidity and liquidity premia across the term structure spectrum, it may also forecast illiquidity as well as returns for other maturities. By examining the return forecasting ability of various bonds according to their on-the-run status and maturity, we are able to shed light on this issue as well.

\section{Basic Statistics}

\section{A. The Data}

We measure liquidity in the Treasury market with proportional quoted spreads. This is a standard measure for the Treasury market. The simple bid-ask spread measure, based on widely available data, is highly correlated with other liquidity measures in the bond market. ${ }^{9}$ The quoted bid and ask prices are from the Center for Research in Security Prices (CRSP) daily Treasury Quotes file from November 1967 to December 2005. The file includes Treasury fixed income securities of 3 and 6 months and 1, 2, 3, 5, 7, 10, 20, and 30 years to maturity. Once issued, the security is considered as on-the-run and the older issues are offthe-run. ${ }^{10}$ The proportional quoted spread for the T-bond market, the difference between ask and bid prices scaled by the midpoint of the posted quote, is computed using quoted ask and bid prices for a particular day (using only 2-sided quotes for the calculation). ${ }^{11}$ The monthly average spread is computed for each security and then equal weighted across different assets for each month.

\footnotetext{
${ }^{9}$ Chordia, Sarkar, and Subrahmanyam (2002) show that daily correlations between quoted and effective spread changes in the bond market are 0.68 over their 9-year sample period, while Chordia et al. (2005) show that daily quoted spreads have a correlation of -0.49 with depth. This indicates that quoted spreads are reasonable liquidity proxies.

${ }^{10}$ This is a standard definition of on-the-run and off-the-run bonds.

${ }^{11}$ Results are substantively unaltered when unscaled (raw) quoted spreads are used as an alternative to proportional quoted spreads.
} 
Our primary motivation in using the CRSP data is to have a long enough time series of illiquidity in order to study the connection between economic environment, liquidity conditions, and prices. Thus, to our knowledge, CRSP is the only data source that allows the usage of a period long enough to subsume a variety of economic events. ${ }^{12}$ Our data have also been used by Goyenko and Ukhov (2009) in their analysis of the economic linkages between the stock and bond markets.

We use 6 bond liquidity series across 3 maturity classes and seasonedness status. The first maturity class is short-term liquidity computed for T-bills with maturity less than or equal to 1 year. The second is the liquidity of the mediummaturity assets obtained from the quotes on 2- to 5-year bonds. The third is the liquidity of the 10-year note, a traditional benchmark. We study the 3 series separately for on-the-run and off-the-run issues.

\section{B. The Impact of Recessions}

Table 1 provides descriptive statistics for the illiquidity series. For the whole sample (Panel A), the spreads for medium- and long-term bonds tend to be wider for off-the-run issues than on-the-run issues. For short-term bonds, spreads of onthe-run issues are on average wider for the whole sample (Panel A). During nonrecessions (Panel C), the average spreads of short-term bonds tend to be very close in magnitude for on-the-run and off-the-run issues. However, both short-term on- and off-the-run spreads increase by more than a factor of 2 during National Bureau of Economic Research (NBER) recessions (Panel B). Medium- and longterm spreads also increase during recessions compared to nonrecessions, but the percentage increase is less dramatic than that for short-term bonds. Thus, spreads are higher during recessions, and their increase is especially pronounced for shortterm maturities.

Panel D of Table 1 reports the difference between long- and short-term spreads for the whole sample and for subsamples. The difference is positive, as the spreads are higher for the long-term bonds. For both on-the-run and off-therun issues, the difference is significantly higher during recessions. This suggests that, as hypothesized in Section II, investors may be shifting into short-term bonds in recessionary periods. ${ }^{13}$

Figures 1 and 2 present graphs for the illiquidity of on-the-run and off-therun issues, respectively, by maturity. Gray bars denote NBER recessions. For the on-the-run bonds, as Figure 1, Graph A shows, the illiquidity of short-term bonds almost always increases during recessions. This pattern is less pronounced for long-term bonds, Graph C, and is nearly absent for medium-term bonds, Graph B. In contrast, for off-the-run bonds, Figure 2, the tendency for illiquidity to increase during recessions is observed across all maturities. This pattern points toward a heterogeneity in liquidity dynamics across on-the-run and off-the-run bonds, which we explore in detail later.

\footnotetext{
${ }^{12}$ In 1996 CRSP switched its data source from the Federal Reserve Bank of New York to GovPX indicative quotes. We address this issue in our robustness checks, described later.

${ }^{13}$ While it would be of interest to confirm this inference using volume data, unfortunately, such data are not available for the bond market over a long enough sample period.
} 
TABLE 1

Descriptive Statistics

In Table 1, bond illiquidity is computed from daily proportional quoted spreads available at CRSP daily Treasury files. BOND-SHORT is the illiquidity of T-bills, BOND-MEDIUM is the illiquidity of 2- to 5-year bonds, and BOND-LONG is the illiquidity of 10-year notes. The most recently issued securities are considered as on-the-run, and the older issues are off-the-run. Recessions are determined by NBER business cycle dates. The sample is from November 1967 to December 2005 (458 months). All numbers (except p-values) are multiplied by 100

\begin{tabular}{lllll}
\multicolumn{2}{c}{ On-the-Run } & \multicolumn{2}{c}{ Off-the-Run } \\
${ }$ BOND-MEDIUM $}$ \\
\end{tabular}

\section{Panel A. The Whole Sample}

\begin{tabular}{|c|c|c|c|c|c|c|}
\hline $\begin{array}{l}\text { Average } \\
\text { Std. dev. } \\
\text { Median }\end{array}$ & $\begin{array}{l}0.032 \\
0.026 \\
0.019\end{array}$ & $\begin{array}{l}0.106 \\
0.147 \\
0.07\end{array}$ & $\begin{array}{l}0.111 \\
0.076 \\
0.099\end{array}$ & $\begin{array}{l}0.025 \\
0.023 \\
0.012\end{array}$ & $\begin{array}{l}0.108 \\
0.062 \\
0.11\end{array}$ & $\begin{array}{l}0.156 \\
0.105 \\
0.142\end{array}$ \\
\hline \multicolumn{7}{|c|}{ Panel B. Recessions (NBER) } \\
\hline $\begin{array}{l}\text { Average } \\
\text { Std. dev. } \\
\text { Median }\end{array}$ & $\begin{array}{l}0.057 \\
0.03 \\
0.066\end{array}$ & $\begin{array}{l}0.124 \\
0.102 \\
0.121\end{array}$ & $\begin{array}{l}0.147 \\
0.082 \\
0.131\end{array}$ & $\begin{array}{l}0.049 \\
0.029 \\
0.054\end{array}$ & $\begin{array}{l}0.149 \\
0.061 \\
0.172\end{array}$ & $\begin{array}{l}0.234 \\
0.105 \\
0.263\end{array}$ \\
\hline \multicolumn{7}{|c|}{ Panel C. No Recessions (NBER) } \\
\hline $\begin{array}{l}\text { Average } \\
\text { Std. dev. } \\
\text { Median }\end{array}$ & $\begin{array}{l}0.027 \\
0.022 \\
0.016\end{array}$ & $\begin{array}{l}0.102 \\
0.153 \\
0.063\end{array}$ & $\begin{array}{l}0.105 \\
0.073 \\
0.093\end{array}$ & $\begin{array}{l}0.02 \\
0.019 \\
0.01\end{array}$ & $\begin{array}{l}0.101 \\
0.059 \\
0.079\end{array}$ & $\begin{array}{l}0.141 \\
0.099 \\
0.108\end{array}$ \\
\hline \multicolumn{7}{|c|}{ Panel D. Spread Difference between Long- and Short-Term Bonds } \\
\hline & \multicolumn{3}{|c|}{ On-the-Run } & \multicolumn{3}{|c|}{ Off-the-Run } \\
\hline & \multicolumn{3}{|c|}{ BOND-LONG - BOND-SHORT } & \multicolumn{3}{|c|}{ BOND-LONG - BOND-SHORT } \\
\hline & Whole Sample & $\underline{\text { Recession }}$ & $\underline{\text { No Recession }}$ & $\underline{\text { Whole Sample }}$ & $\underline{\text { Recession }}$ & $\underline{\text { No Recession }}$ \\
\hline $\begin{array}{l}\text { Diff. } \\
\text { p-value }\end{array}$ & $\begin{array}{l}0.08 \\
0.00\end{array}$ & $\begin{array}{l}0.09 \\
0.00\end{array}$ & $\begin{array}{l}0.078 \\
0.00\end{array}$ & $\begin{array}{l}0.131 \\
0.00\end{array}$ & $\begin{array}{l}0.185 \\
0.00\end{array}$ & $\begin{array}{l}0.121 \\
0.00\end{array}$ \\
\hline
\end{tabular}

\section{Vector Autoregression Analysis}

Our goal is to explore the intertemporal associations between bond illiquidity of different maturities, returns, volatility, and macroeconomic variables that affect bond prices and can also have an impact on illiquidity. In particular, we are interested in determining what forces drive the dynamics of illiquidity of on-the-run and off-the-run issues and what relations hold between the illiquidity of different maturities and bond returns. We run our analysis separately for on-the-run and off-the-run issues.

\section{A. The Explanatory Variables}

We use an adjusted time series of illiquidity after removing a time trend and the square of the time trend. Our first set of explanatory variables for illiquidity dynamics emanates from within the bond markets, and our second set comprises the macroeconomic variables discussed in Section II.

The bond market variables consist of returns and volatility. Earlier work (e.g., Chordia et al. (2001)) argues that returns may influence future trading behavior, which may, in turn, affect liquidity. For instance, the portfolio-rebalancing arguments of Merton (1971) imply return-dependent investing behavior, and such order imbalances in response to a price change may strain liquidity. Thus, as our first set of explanatory variables, we use monthly returns (computed using 
FIGURE 1

Illiquidity of On-the-Run Treasuries

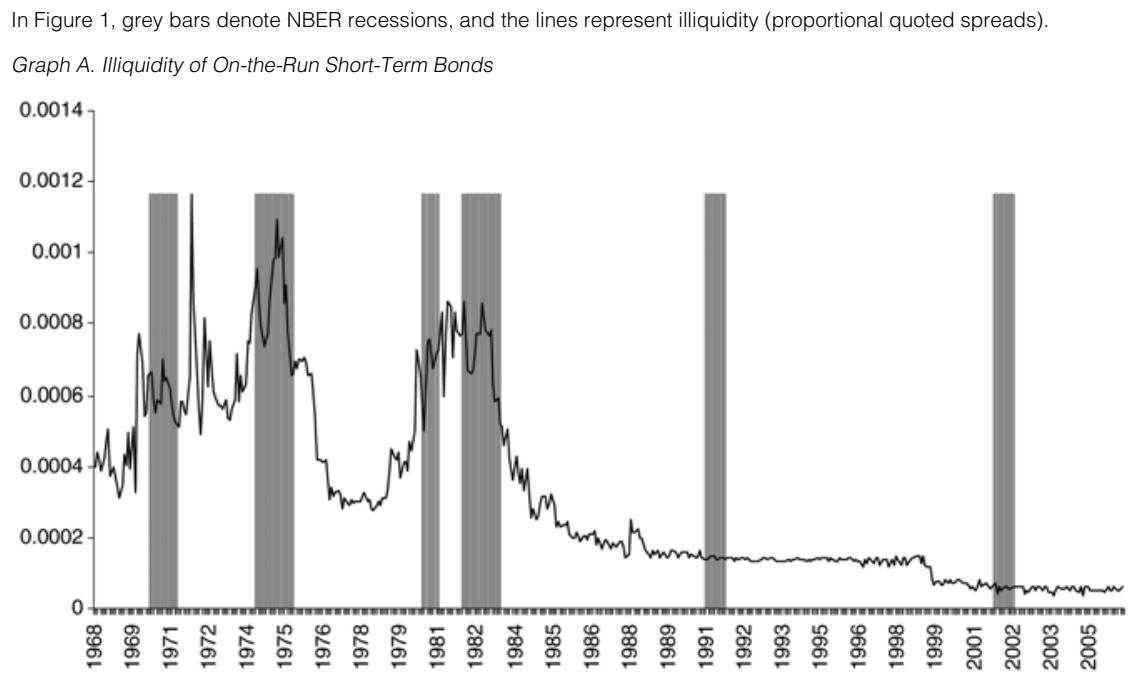

Graph B. Illiquidity of On-the-Run Medium-Term Bonds

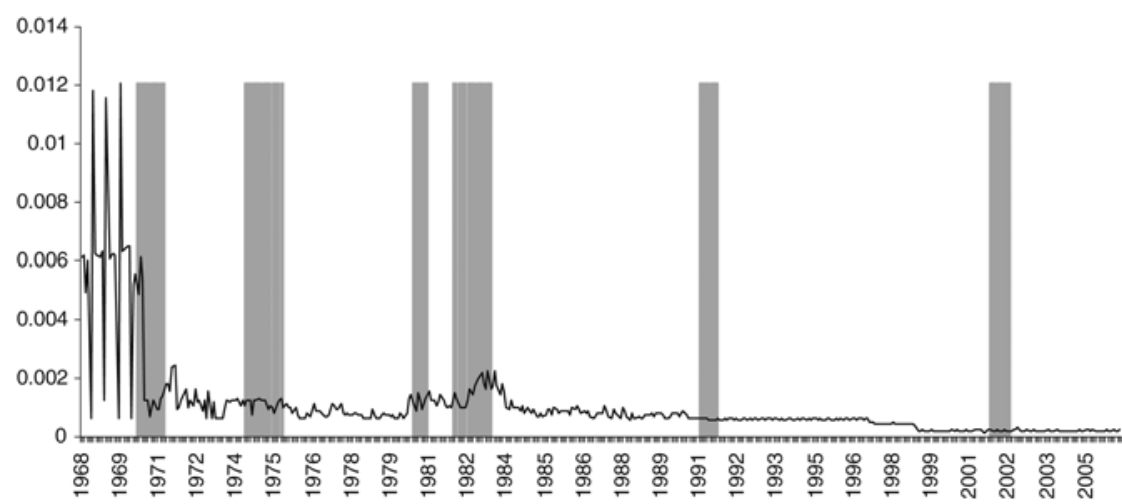

Graph C. Illiquidity of On-the-Run Long-Term Bonds

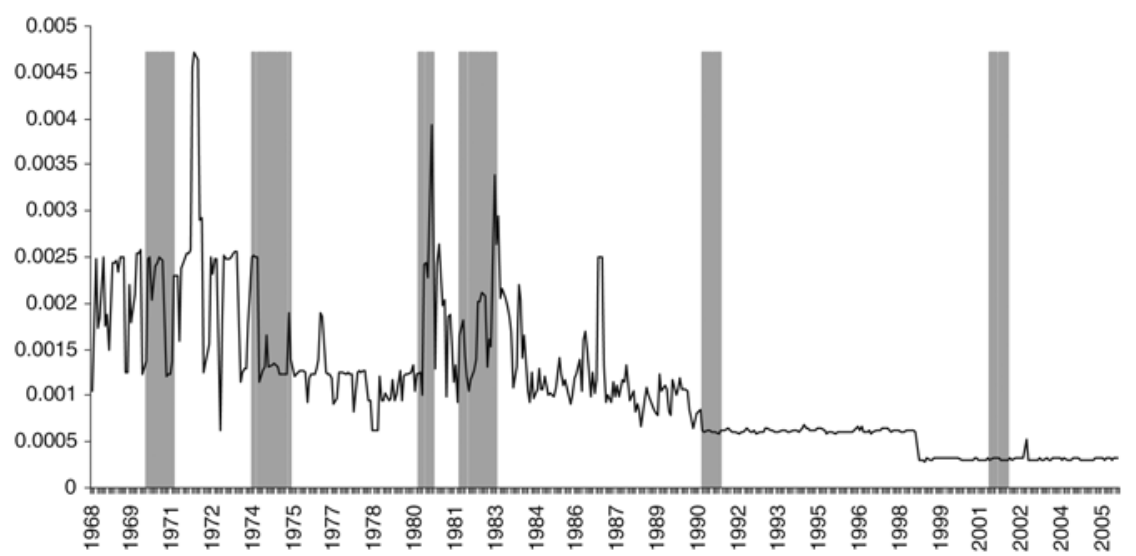


FIGURE 2

\section{Illiquidity of Off-the-Run Treasuries}

In Figure 2, grey bars denote NBER recessions, and the lines represent illiquidity (proportional quoted spreads). Graph A. Illiquidity of Off-the-Run Short-Term Bonds

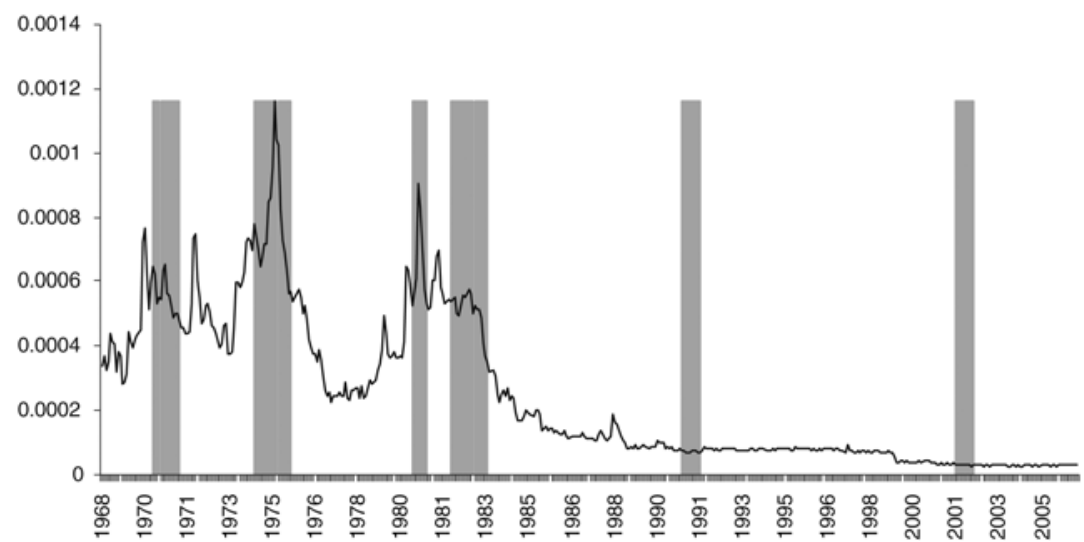

Graph B. Illiquidity of Off-the-Run Medium-Term Bonds

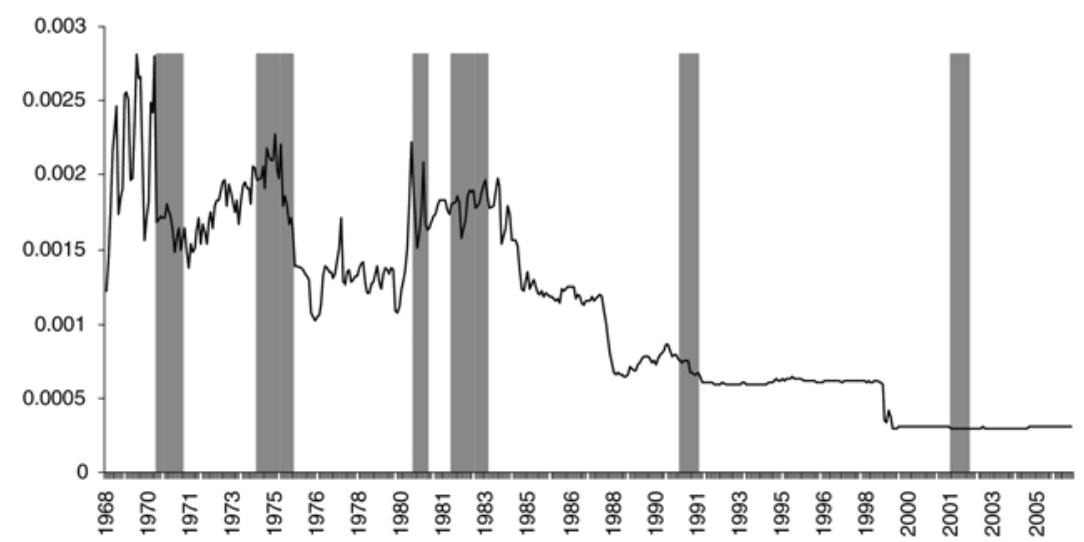

Graph C. Illiquidity of Off-the-Run Long-Term Bonds

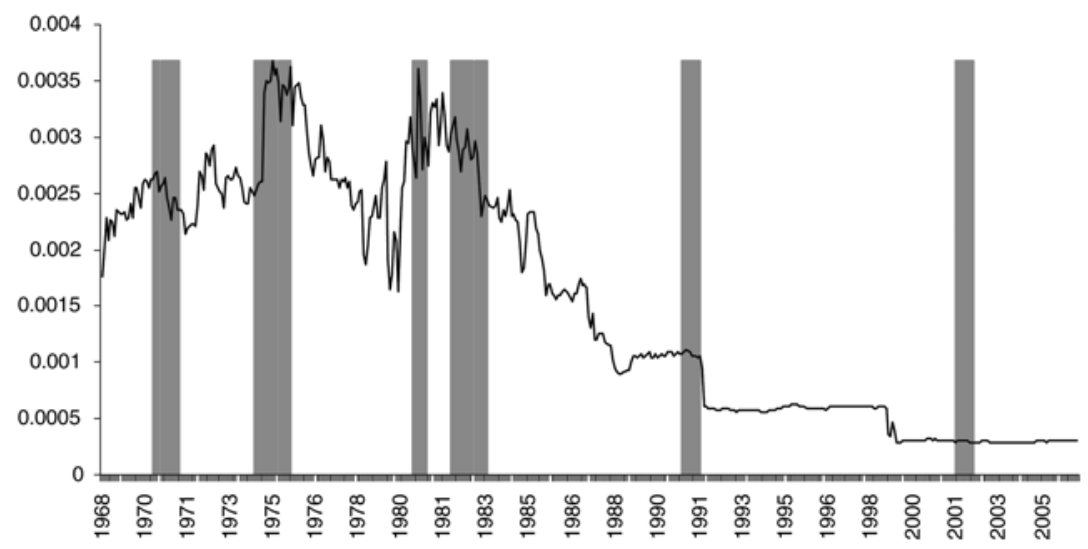


end-of-month prices) of 3 maturity ranges: short, medium, and long. To capture price variation in the short-maturity range, we use the return on the 3-month T-bill (RET1). Returns on 5- and 10-year notes represent medium (RET5) and long (RET10) maturity, respectively. ${ }^{14}$ All returns are from the CRSP Treasury monthly file.

Benston and Hagerman (1974) suggest a role for volatility in causing illiquidity by indicating that increased volatility implies increased inventory risk and hence, a higher bid-ask spread (see Duffie, Gârleanu, and Pedersen (2007) for a similar argument). We thus include return volatility as an explanatory variable. To measure the volatility in the Treasury market, we use the volatility of a 10-year note. ${ }^{15}$ The volatility is obtained as monthly standard deviation of daily returns available from CRSP daily Treasury files.

With regard to macroeconomic variables (motivated in Section II), inflation is obtained as the growth rate in the Consumer Price Index. The term premium (TERM) is defined as the difference between yields on a 10-year T-note and 3month T-bill. The default premium (DEF) is the difference between yields on long-term BAA- and AAA-rated bonds. As indicators of the monetary policy stance, we include the FED. Since the unit root test indicates nonstationarity in FED, the subsequent analysis uses first differences. ${ }^{16}$ The data are from the Federal Reserve Bank of St. Louis.

We use VAR analysis to study the joint dynamics of the variables. ${ }^{17}$ In accordance with the Akaike information criterion (AIC) and Schwarz Bayesian information criterion (BIC), we estimate the VAR system with 1 lag. This system is described in the Appendix. Table 2 reports pairwise Granger causality tests between the endogenous variables in the VAR. For the null hypothesis that variable $i$ does not Granger-cause variable $j$, we test whether the lag coefficients of $i$ are jointly 0 when $j$ is the dependent variable in the VAR. The cell associated with the $i$ th row variable and the $j$ th column variable shows the $\chi^{2}$ statistics and corresponding $p$-values in parentheses.

\section{B. Granger Causality Tests}

The causality tests for illiquidity series across maturities are presented in Panel A of Table 2. For both on-the-run and off-the-run issues, illiquidity of short-term bonds Granger-causes illiquidity of both the other maturities. Reverse

\footnotetext{
${ }^{14}$ The VAR analysis includes these return variables linearly, so that the coefficients capture the incremental effect of one return after accounting for the other return.

${ }^{15}$ Our results do not change if we use the volatility of 5-year bonds. For both bonds and bills, we chose to use the longer-term volatility as a conservative measure of inventory risk. The basic notion is that liquidity is inversely related to volatility, so if we use, for example, the volatility of bills, then this choice likely may not reflect inventory risk for bonds. And including separate measures of volatility would have increased the number of variables of VARs in our system, which would have made the analysis cumbersome.

${ }^{16}$ While our hypothesis is that increases in the FED would reduce liquidity due to increases in financing costs for both dealers and traders, we are agnostic as to the direct effect of the FED on the return premium for illiquidity. Indirectly, of course, we hypothesize that the FED affects liquidity, and in turn the total liquidity premium.

${ }^{17}$ See Chordia et al. (2005) for a discussion of why the VAR is appropriate in dynamic analyses of liquidity across markets.
} 
causality from longer-term bonds to shorter-term bonds is less consistent. For offthe-run bonds, the causality goes in the reverse direction from medium to short, while for on-the-run bonds it goes from long to medium. The overall evidence thus indicates that illiquidity shocks are largely transmitted from the short end to the long end. Beber, Brandt, and Kavajecz (2009) find that liquid Euro-area bonds attract more order flow, presumably both informed and uninformed. This suggests that the liquidity of short-term bonds, as the most liquid asset class, may reflect information before other maturities. Our results are consistent with this notion.

TABLE 2

\title{
Granger Causality Tests
}

\begin{abstract}
Table 2 presents $\chi^{2}$ statistics and $p$-values (in parentheses) of pairwise Granger causality tests between endogenous VAR variables. The null hypothesis is that the row variable does not Granger-cause the column variable. Bond illiquidity estimates are based on proportional quoted spreads across bonds of 3 types of maturities: short (with maturity less than or equal to 1 year), medium (with maturity between 2 and 5 years), and long (with 10 years to maturity). RET1 is the return on 3-month T-bills, RET5 is the return on 5-year notes, and RET10 is the return on 10-year notes. Bond returns are from CRSP fixed-term indices files. VOLAT is the volatility of returns on a 10-year note computed as the standard deviation of daily returns over each month. DEF is the default premium, measured as the difference between yields on long-term BAA-rated and AAA-rated bonds. TERM is the term premium, defined as the difference between yields on a 10-year T-note and 3-month T-bill. FED is the federal funds rate (indicator of the monetary policy stance). INFL is inflation. The sample is from November 1967 to December 2005 (458 months). Numbers in bold indicate significance at the $5 \%$ level.
\end{abstract}

\begin{tabular}{lcc}
\multicolumn{3}{c}{ On-the-Run } \\
\hline BOND- & BOND- & BOND- \\
SHORT & MEDIUM & LONG \\
\hline
\end{tabular}

\begin{tabular}{lcc}
\multicolumn{3}{c}{ Off-the-Run } \\
\hline BOND- & BOND- & BOND- \\
SHORT & MEDIUM & LONG
\end{tabular}

Panel A. Illiquidity Series across Maturities

\begin{tabular}{|c|c|c|c|}
\hline \multicolumn{2}{|l|}{ BOND-SHORT } & \multirow[t]{2}{*}{$\begin{array}{l}11.34 \\
(0.001)\end{array}$} & $\begin{array}{l}5.28 \\
(0.022)\end{array}$ \\
\hline BOND-MEDIUM & $\begin{array}{l}4.19 \\
(0.041)\end{array}$ & & $\begin{array}{l}0.01 \\
(0.912)\end{array}$ \\
\hline \multirow[t]{2}{*}{ BOND-LONG } & $\begin{array}{l}0.86 \\
(0.355)\end{array}$ & $\begin{array}{l}0.05 \\
(0.820)\end{array}$ & \\
\hline & $\begin{array}{l}\text { BOND- } \\
\text { SHORT } \\
\end{array}$ & $\begin{array}{l}\text { BOND- } \\
\text { MEDIUM } \\
\end{array}$ & $\begin{array}{l}\text { BOND- } \\
\text { LONG }\end{array}$ \\
\hline \multicolumn{4}{|l|}{ Panel B. } \\
\hline RET1 & $\begin{array}{l}0.11 \\
(0.738)\end{array}$ & $\begin{array}{c}1.11 \\
(0.292)\end{array}$ & $\begin{array}{l}0.40 \\
(0.526)\end{array}$ \\
\hline RET5 & $\begin{array}{l}8.64 \\
(0.003)\end{array}$ & $\begin{array}{c}0.12 \\
(0.73)\end{array}$ & $\begin{array}{l}0.01 \\
(0.928)\end{array}$ \\
\hline RET10 & $\begin{array}{l}10.43 \\
(0.001)\end{array}$ & $\begin{array}{c}1.54 \\
(0.214)\end{array}$ & $\begin{array}{l}0.01 \\
(0.905)\end{array}$ \\
\hline VOLAT & $\begin{array}{c}3.78 \\
(0.05)\end{array}$ & $\begin{array}{l}50.69 \\
(0.00)\end{array}$ & $\begin{array}{l}21.92 \\
(0.00)\end{array}$ \\
\hline DEF & $\begin{array}{l}0.05 \\
(0.832)\end{array}$ & $\begin{array}{l}0.08 \\
(0.771)\end{array}$ & $\begin{array}{l}9.05 \\
(0.003)\end{array}$ \\
\hline TERM & $\begin{array}{l}5.31 \\
(0.021)\end{array}$ & $\begin{array}{l}0.36 \\
(0.549)\end{array}$ & $\begin{array}{l}0.2 \\
(0.6587)\end{array}$ \\
\hline FED & $\begin{array}{l}5.88 \\
(0.015)\end{array}$ & $\begin{array}{l}0.01 \\
(0.916)\end{array}$ & $\begin{array}{l}2.9 \\
(0.089)\end{array}$ \\
\hline INFL & $\begin{array}{l}5.15 \\
(0.023)\end{array}$ & $\begin{array}{c}1.74 \\
(0.188)\end{array}$ & $\begin{array}{c}0.33 \\
(0.563)\end{array}$ \\
\hline
\end{tabular}

BOND-SHORT

$\begin{array}{cccc}\mathbf{1 0 . 2 5} & 1.17 & 0.97 & \mathbf{7 . 6 8} \\ \mathbf{( 0 . 0 0 1 )} & (0.279) & (0.325) & \mathbf{( 0 . 0 0 6 )} \\ 0.63 & 0.16 & 2.09 & \mathbf{7 . 4 3} \\ (0.426) & (0.689) & (0.148) & \mathbf{( 0 . 0 0 6 )} \\ 0.06 & 0.39 & 0.00 & 0.12 \\ (0.812) & (0.533) & \begin{array}{c}(0.963) \\ (0.725)\end{array} \\ & & & \text { (continued on next page) }\end{array}$




\begin{tabular}{|c|c|c|c|c|c|c|c|}
\hline \multicolumn{8}{|c|}{$\begin{array}{c}\text { TABLE } 2 \text { (continued) } \\
\text { Granger Causality Tests }\end{array}$} \\
\hline & $\begin{array}{l}\text { BOND- } \\
\text { SHORT } \\
\end{array}$ & $\begin{array}{l}\text { BOND- } \\
\text { MEDIUM }\end{array}$ & $\begin{array}{l}\text { BOND- } \\
\text { LONG }\end{array}$ & RET1 & RET5 & $\underline{\text { RET10 }}$ & VOLAT \\
\hline \multicolumn{8}{|c|}{ Panel C. Off-the-Run Illiquidity and Other Endogenous Variables } \\
\hline RET1 & $\begin{array}{l}0.73 \\
(0.392)\end{array}$ & $\begin{array}{l}5.79 \\
(0.016)\end{array}$ & $\begin{array}{l}1.81 \\
(0.178)\end{array}$ & & & & \\
\hline RET5 & $\begin{array}{l}28.80 \\
(0.00)\end{array}$ & $\begin{array}{l}0.12 \\
(0.728)\end{array}$ & $\begin{array}{l}11.29 \\
(0.001)\end{array}$ & & & & \\
\hline RET10 & $\begin{array}{c}20.84 \\
(0.00)\end{array}$ & $\begin{array}{l}1.24 \\
(0.265)\end{array}$ & $\begin{array}{l}6.21 \\
(0.013)\end{array}$ & & & & \\
\hline VOLAT & $\begin{array}{l}0.19 \\
(0.661)\end{array}$ & $\begin{array}{l}9.63 \\
(0.002)\end{array}$ & $\begin{array}{c}1.04 \\
(0.309)\end{array}$ & & & & \\
\hline DEF & $\begin{array}{l}8.62 \\
(0.003)\end{array}$ & $\begin{array}{l}1.7 \\
(0.193)\end{array}$ & $\begin{array}{l}0.41 \\
(0.522)\end{array}$ & & & & \\
\hline TERM & $\begin{array}{l}7.13 \\
(0.008)\end{array}$ & $\begin{array}{l}5.63 \\
(0.018)\end{array}$ & $\begin{array}{l}1.76 \\
(0.185)\end{array}$ & & & & \\
\hline FED & $\begin{array}{l}28.61 \\
(0.00)\end{array}$ & $\begin{array}{l}5.53 \\
(0.019)\end{array}$ & $\begin{array}{l}1.04 \\
(0.307)\end{array}$ & & & & \\
\hline INFL & $\begin{array}{l}7.95 \\
(0.005)\end{array}$ & $\begin{array}{c}0.72 \\
(0.398)\end{array}$ & $\begin{array}{l}8.7 \\
(0.003)\end{array}$ & & & & \\
\hline BOND-SHORT & & & & $\begin{array}{l}11.57 \\
(0.001)\end{array}$ & $\begin{array}{l}2.87 \\
(0.091)\end{array}$ & $\begin{array}{l}1.76 \\
(0.185)\end{array}$ & $\begin{array}{l}6.36 \\
(0.012)\end{array}$ \\
\hline BOND-MEDIUM & & & & $\begin{array}{l}2.82 \\
(0.093)\end{array}$ & $\begin{array}{l}0.01 \\
(0.907)\end{array}$ & $\begin{array}{l}0.3 \\
(0.583)\end{array}$ & $\begin{array}{l}19.36 \\
(0.00)\end{array}$ \\
\hline BOND-LONG & & & & $\begin{array}{c}9.29 \\
(0.002)\end{array}$ & $\begin{array}{l}1.3 \\
(0.254)\end{array}$ & $\begin{array}{l}0.38 \\
(0.539)\end{array}$ & $\begin{array}{l}7.1 \\
(0.008)\end{array}$ \\
\hline
\end{tabular}

Panels B and C of Table 2 present the results for causality tests between illiquidity and other endogenous variables for on- and off-the-run issues, respectively. For brevity, we focus on Granger-causation involving the liquidity variables. We find that all 4 macro variables (DEF, TERM, FED, and INFL) cause short-term off-the-run illiquidity. The last 3 variables also cause on-the-run short-term bond illiquidity. The impact of these variables on longer-term illiquidity is a bit mixed. Overall, we can conclude that macroeconomic variables do forecast bond market illiquidity, especially at the short end of the term structure spectrum. We also find that volatility has a causality effect on illiquidity of on-the-run issues across all maturity ranges, and on illiquidity of medium off-the-run issues. We will reexamine these findings in the next subsection when we present impulse response functions (IRFs).

For off-the-run bonds, we find that illiquidity of all maturities Grangercauses volatility. Also, the illiquidity of short-term bonds causes the return of short-and medium-term bonds. The effect of on-the-run illiquidity on bond returns and volatility is less pronounced. Overall, the evidence for off-the-run illiquidity supports the literature on liquidity premium in the T-bond markets (Amihud and Mendelson (1991)).

Note that the Granger causality results are based on analysis of the coefficients from a single equation and do not account for the joint dynamics implied by the VAR system. A clearer picture can potentially emerge if we use IRFs. The IRF traces the impact of a 1-time, unit standard deviation, positive shock to one variable on the current and future values of the endogenous variables. Since innovations are correlated, they need to be orthogonalized. They are computed 
using standard Cholesky decompositions of the VAR residuals and assuming that innovations in the variables placed earlier in the VAR have greater effects on the following variables. Thus, one approach is to order the variables according to the order in which they influence the other variables.

Based on the preceding observation, we place macroeconomic variables in the beginning of the VAR ordering, since while financial markets respond to monetary policy, the latter is relatively exogenous to the financial system. There are precedents for putting monetary policy instruments before financial variables in the VAR ordering (Thorbecke (1997), Chordia et al. (2005)). The ordering of macroeconomic variables (INFL, FED) is based on conventional practice in the macroeconomic literature. They are followed by the business cycle variables, TERM and DEF. Relying on prior evidence (Chordia et al. (2005)), we order the rest of the variables as follows: Volatility, RET1, RET5, RET10, BOND-SHORT, BOND-MEDIUM, and BOND-LONG. The conclusions about IRFs are insensitive to the ordering of market variables.

\section{VAR Innovations: Correlation Matrix}

Before proceeding to impulse response analyses, it is of interest to examine contemporaneous relations between innovations in the variables. Accordingly, Panels A and B of Table 3 report the contemporaneous correlation matrix of the VAR innovations for on- and off-the-run illiquidity, respectively. Again, we focus only on the correlations involving the liquidity variables. Correlations in innovations of illiquidity across maturities are significant only for off-the-run illiquidity. Shocks to TERM are negatively correlated with innovations in illiquidity. Thus, an increase in the term spread is accompanied by an improvement in bond market liquidity. This finding is contrary to the initial hypothesis in Section II and deserves further analysis in future work. Shocks to volatility are generally positively correlated with innovations in illiquidity, with the exception of the onthe-run bond-medium illiquidity, which has an anomalous negative correlation. Innovations in FED are positively correlated with illiquidity of on-the-run and off-the-run issues (i.e., monetary policy tightening is associated contemporaneously with an increase in bond spreads).

We find that shocks to off-the-run short-term illiquidity are significantly negatively correlated with returns across all maturities. This is consistent with the results of Amihud (2002) for the stock market: Positive shocks to spreads are accompanied by a contemporaneous decrease in prices, consistent with the presence of a liquidity premium. Return correlations with illiquidity are largely insignificant for illiquidity of other types of bonds, which suggests a special role of the off-the-run short-term bond illiquidity in affecting bond prices across all maturities. We now shed more light on these economic relations by examining IRFs.

\section{Impulse Response Functions: Illiquidity}

Graph A of Figure 3 illustrates the response of short-bond off-the-run illiquidity to a unit standard deviation change in a particular variable, traced forward over a period of 24 months. In the graphs, month 0 gives the contemporaneous impact and months 1-24 plot the effect from +1 to +24 months. Bootstrap $95 \%$ 
TABLE 3

Contemporaneous Correlation between VAR Innovations

Table 3 presents results from a VAR with endogenous variables INFL, FED, TERM, DEF, VOLAT, RET1, RET5, RET10, BOND-SHORT, BOND-MEDIUM, and BOND-LONG. It is estimated with 1 lag and a constant term. Bond illiquidity estimates are based on proportional quoted spreads across bonds of 3 types of maturities: short (with maturity less than or equal to 1 year), medium (with maturity between 2 and 5 years), and long (with 10 years to maturity). RET1 is the return on 3-month T-bill, RET5 is the return on 5-year notes, and RET10 is the return on a 10-year note. Bond returns are from CRSP fixed-term indices files. VOLAT is the volatility of returns on a 10-year note computed as standard deviation of daily returns over each month. DEF is the default premium, measured as the difference between yields on long-term BAA-rated and AAA-rated bonds. TERM is the term premium, defined as the difference between yields on a 10-year T-note and 3-month T-bill. FED is the federal funds rate (indicator of the monetary policy stance). INFL is inflation. The sample is from November 1967 to December 2005 (458 months). Numbers in bold denote significance at $5 \%$ level.

\begin{tabular}{|c|c|c|c|c|c|c|c|c|c|c|c|}
\hline & INFL & $\underline{F E D}$ & TERM & $\underline{D E F}$ & VOLAT & RET1 & RET5 & $\underline{\text { RET10 }}$ & $\begin{array}{l}\text { BOND- } \\
\text { SHORT }\end{array}$ & $\begin{array}{c}\text { BOND- } \\
\text { MEDIUM } \\
\end{array}$ & $\begin{array}{l}\text { BOND- } \\
\text { LONG } \\
\end{array}$ \\
\hline \multicolumn{12}{|c|}{ Panel A. On-the-Run Illiquidity } \\
\hline $\begin{array}{l}\text { BOND- } \\
\text { SHORT }\end{array}$ & 0.04 & 0.16 & -0.14 & -0.05 & 0.08 & -0.09 & -0.10 & -0.07 & 1.00 & & \\
\hline $\begin{array}{l}\text { BOND- } \\
\text { MEDIUM }\end{array}$ & 0.01 & 0.10 & -0.13 & -0.09 & -0.17 & 0.02 & 0.01 & 0.06 & -0.01 & 1.00 & \\
\hline $\begin{array}{l}\text { BOND- } \\
\text { LONG }\end{array}$ & 0.02 & 0.03 & -0.13 & -0.02 & 0.10 & 0.03 & 0.05 & 0.09 & 0.06 & 0.06 & 1.00 \\
\hline \multicolumn{12}{|c|}{ Panel B. Off-the-Run Illiquidity } \\
\hline $\begin{array}{l}\text { BOND- } \\
\text { SHORT }\end{array}$ & 0.08 & 0.27 & -0.24 & -0.01 & 0.17 & -0.16 & -0.18 & -0.11 & 1.00 & & \\
\hline $\begin{array}{l}\text { BOND- } \\
\text { MEDIUM }\end{array}$ & 0.02 & 0.01 & -0.06 & -0.07 & 0.02 & 0.01 & 0.02 & 0.07 & -0.03 & 1.00 & \\
\hline $\begin{array}{l}\text { BOND- } \\
\text { LONG }\end{array}$ & 0.11 & 0.25 & -0.24 & -0.04 & 0.08 & 0.00 & -0.14 & -0.05 & 0.27 & 0.26 & 1.00 \\
\hline
\end{tabular}

confidence bands are provided to gauge the statistical significance of the responses. The figure indicates that short-bond illiquidity increases in response to inflation shocks as well as to monetary tightening associated with a positive shock to FED. TERM and DEF do not have an immediate impact on short-term bond illiquidity.

An innovation in short- and medium-term bond returns results in a reduction in short-term bond illiquidity, while a shock to volatility predicts an increase in short-term illiquidity. These results are consistent with those for the stock market of Chordia et al. (2001), who show that up-market moves have a positive effect on liquidity, and with models of microstructure, which argue that increased volatility, by increasing inventory risk, tends to increase market illiquidity. Short-bond illiquidity increases contemporaneously in response to its own shock, with the response decaying rapidly. The effect of illiquidity of other maturities on short-bond illiquidity is insignificant.

Graphs B and C of Figure 3 present the IRFs for medium- and long-bond illiquidity, respectively. Similarly to short-bond illiquidity, a shock to inflation increases long-bond illiquidity (Graph C). However, inflation shocks have no significant impact on medium-bond illiquidity (Graph B). As in Graph A, a shock to FED forecasts an increase in medium- and long-bond illiquidity. Thus, monetary policy tightening appears to have an effect across illiquidity of all maturities. TERM and DEF have no significant impact on illiquidity. While innovations in returns have no significant effect on medium-bond illiquidity, innovations to shortand medium-term bond returns decrease long-bond illiquidity. Volatility increases bond illiquidity across all maturities with a very short-lived effect for long-bond illiquidity. Across illiquidity series, while medium-bond and short-bond illiquidities are only exposed to their own shocks, long-bond illiquidity increases in 
response to its own positive shock as well as to the shocks in medium- and shortbond illiquidity. Thus, overall, it may be concluded that shocks to illiquidity at the short end are transferred into the illiquidity of the longer ends, while the reverse is not true.

\section{FIGURE 3}

\section{Off-the-Run Illiquidity}

In Figure 3, we plot impulse response functions (IRFs) for off-the-run illiquidity (the response variable) to a unit standard deviation change in a particular variable, traced forward over a period of 24 months. Response to Cholesky 1 standard deviation. Dashed lines represent bootstrap 95\% confidence bands derived via 1,000 bootstrap simulations.

Graph A. Response of Short-Bond Illiquidity to Endogenous Variables
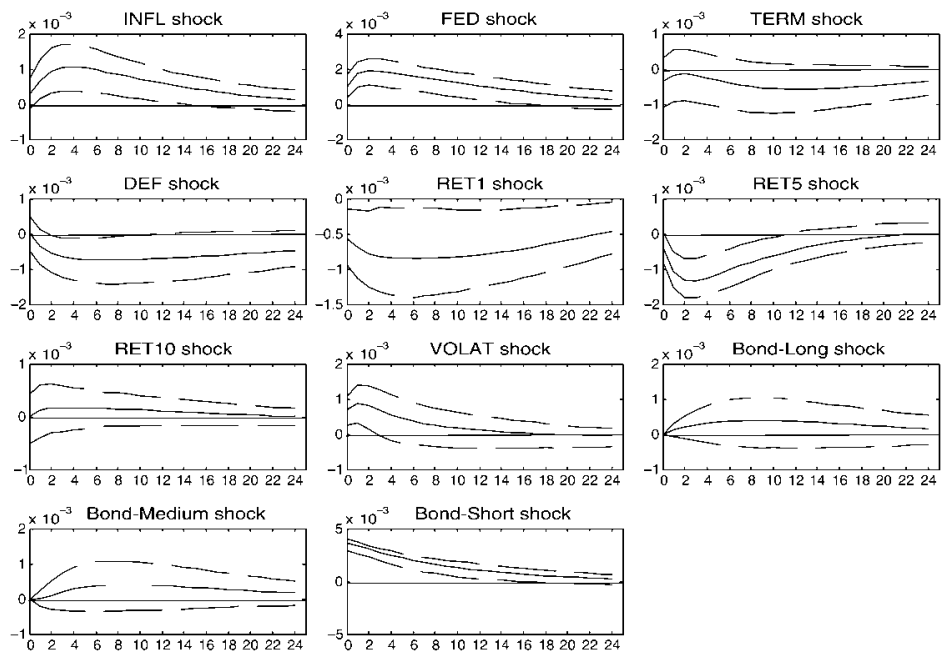

Graph B. Response of Medium-Bond Illiquidity to Endogenous Variables
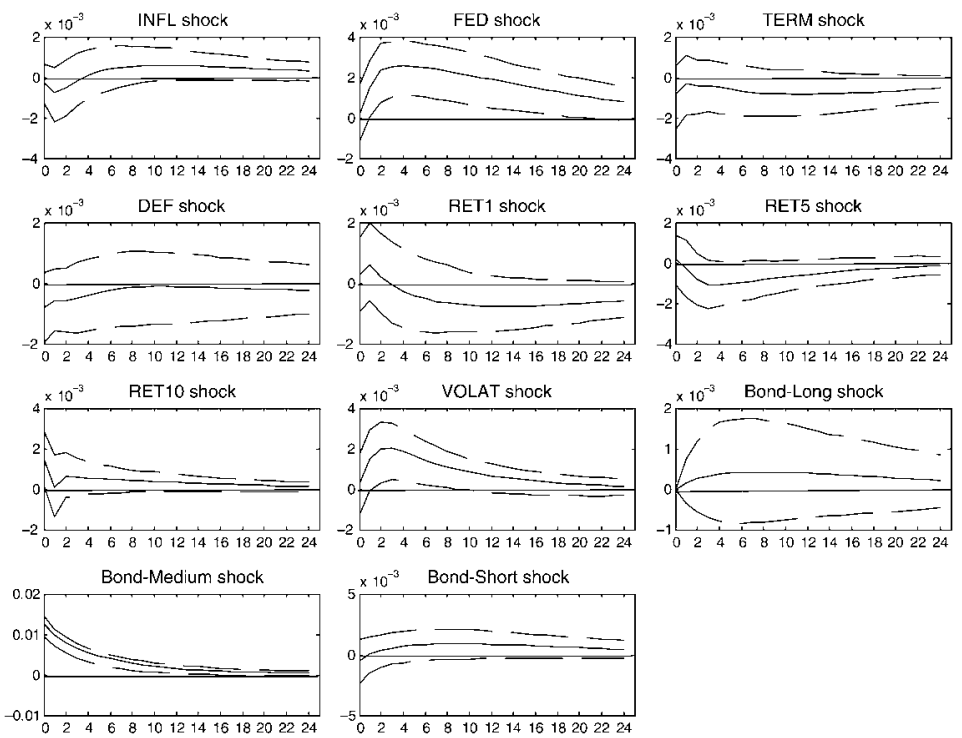
FIGURE 3 (continued)

Off-the-Run Illiquidity

Graph C. Response of Long-Bond Illiquidity to Endogenous Variables
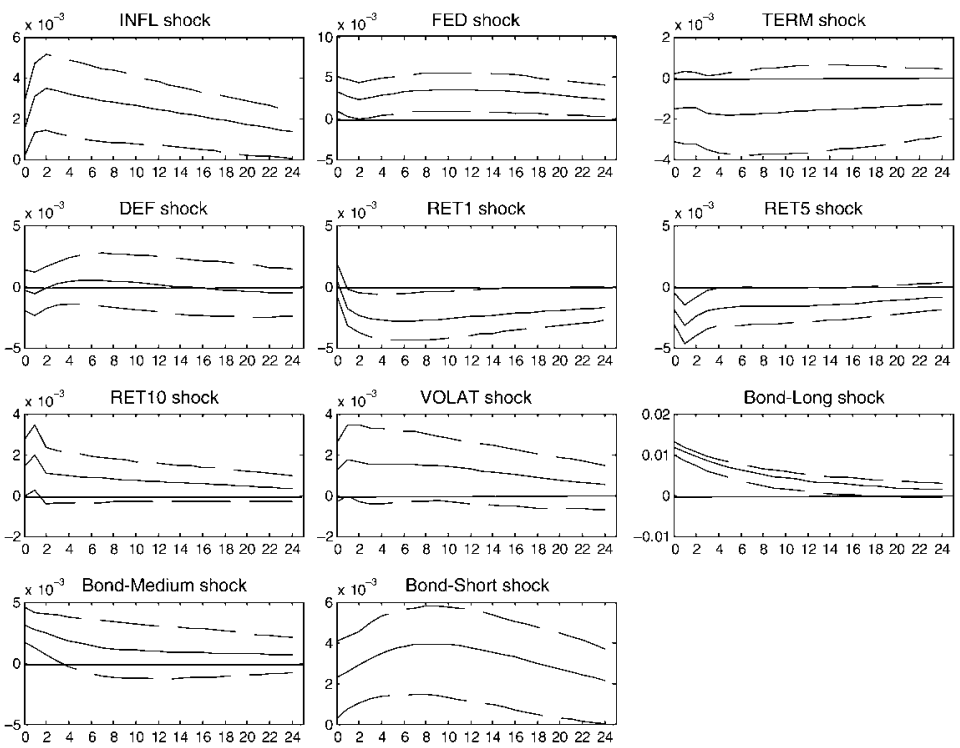

The results for on-the-run illiquidity can be summarized as follows: ${ }^{18}$ Inflation, TERM, and DEF have no significant impact on on-the-run illiquidity. In contrast to off-the-run illiquidity, a shock to FED only increases the illiquidity of short-term bonds. Bond returns have no immediate significant impact on illiquidity, while shocks to volatility increase illiquidity across all maturities. Thus, volatility forecasts illiquidity across all maturities for both on- and off-the-run bonds. Overall, we conclude that the dynamics of on-the-run illiquidity seem to be driven by a relatively narrow set of economic variables compared to off-therun illiquidity. While inflation, FED, bond returns and volatility are significant determinants of off-the-run illiquidity, on-the-run illiquidity seems to be affected mainly by volatility.

To quantitatively demonstrate the difference between on-the-run and offthe-run spreads, Table 4 provides a variance decomposition of illiquidity across different maturities and on-the-run status. We find that considerable variation in off-the-run illiquidity is attributed to monetary policy and inflation. For short-term bonds, monetary policy (FED) explains only $4 \%$ of the variance of on-the-run spreads at short lags (Panel A), but the corresponding number reaches almost $13 \%$ for off-the-run spreads (Panel B). For medium-term bonds, FED explains approximately 7 times more variation (at longer lags) in off-the-run illiquidity (Panel B) than in on-the-run illiquidity (Panel A). For long-term bond illiquidity, FED explains $9 \%$ to $13 \%$ of variation in off-the-run illiquidity at longer lags (Panel B) compared to $0.7 \%$ to $1.7 \%$ of variation in the on-the-run counterparts.

\footnotetext{
${ }^{18}$ We do not report these results for brevity. They are available from the authors.
} 
Inflation shocks, too, have a considerably higher impact on the off-the-run spreads than on the on-the-run spreads. For short-term bonds, inflation explains $6 \%$ of the variance of off-the-run illiquidity at long lags, compared to $2 \%-3 \%$ for on-therun illiquidity. For long-term bonds, inflation explains up to $8 \%$ of the variance for off-the-run illiquidity (at long lags), versus less than $1 \%$ of the variation for on-the-run illiquidity. Overall, the finding that macro variables have a bigger impact on off-the-run spreads than on-the-run spreads complements and supports the evidence from the IRFs.

TABLE 4

Variance Decomposition of Bond Illiquidity

Table 4 presents the variance decompositions computed from a VAR with endogenous variables INFL, FED, TERM, DEF, VOLAT, RET1, RET5, RET10, BOND-SHORT, BOND-MEDIUM, and BOND-LONG. They are estimated with 1 lag and a constant term. Bond illiquidity estimates are based on proportional quoted spreads across bonds of 3 types of maturities: short (with maturity less than or equal to 1 year), medium (with maturity between 2 and 5 years), and long (with 10 years to maturity). RET1 is the return on a 3-month T-bill, RET5 is the return on 5-year notes, and RET10 is the return on 10-year notes. Bond returns are from CRSP fixed-term indices files. VOLAT is the volatility of returns on a 10-year note computed as standard deviation of daily returns over each month. DEF is the default premium, measured as the difference between yields on long-term BAA-rated and AAA-rated bonds. TERM is the term premium, defined as the difference between yields on a 10-year T-note and 3-month T-bill. FED is the federal funds rate (indicator of the monetary policy stance). INFL is inflation. The sample is from November 1967 to December 2005 (458 months).

$$
\text { Lag INFL FED TERM DEF VOLAT RET1 RET5 RET10 } \begin{array}{llll}
\text { BOND- } & \text { BOND- } & \text { BOND- } \\
\text { MEDIUM } & \text { LONG }
\end{array}
$$

Panel A. Variance Decomposition (\%) of On-the-Run Illiquidity

\begin{tabular}{lrrrrrrrrrrrr} 
BOND- & 2 & 0.52 & 4.04 & 0.17 & 0.28 & 2.21 & 0.97 & 1.19 & 0.30 & 89.74 & 0.58 & 0.02 \\
SHORT & 12 & 2.37 & 12.89 & 1.21 & 0.15 & 2.04 & 3.80 & 2.12 & 0.19 & 73.02 & 1.73 & 0.49 \\
& 24 & 2.59 & 15.20 & 2.39 & 0.14 & 1.76 & 4.91 & 1.92 & 0.17 & 68.35 & 1.94 & 0.63 \\
BOND- & 2 & 0.21 & 0.83 & 0.78 & 0.58 & 9.10 & 0.36 & 0.21 & 1.41 & 1.36 & 85.11 & 0.04 \\
MEDIUM & 12 & 0.53 & 1.46 & 0.71 & 0.64 & 14.65 & 0.41 & 0.22 & 1.22 & 8.11 & 71.97 & 0.08 \\
& 24 & 0.54 & 1.46 & 0.71 & 0.67 & 14.50 & 0.44 & 0.24 & 1.22 & 8.88 & 71.26 & 0.08 \\
BOND- & 2 & 0.05 & 0.10 & 1.67 & 0.01 & 4.51 & 0.25 & 0.04 & 1.94 & 0.25 & 0.18 & 91.01 \\
LONG & 12 & 0.30 & 0.65 & 1.41 & 1.24 & 12.38 & 0.66 & 0.22 & 1.52 & 2.18 & 0.47 & 78.97 \\
& 24 & 0.42 & 1.69 & 1.38 & 1.76 & 12.13 & 0.64 & 0.35 & 1.47 & 3.17 & 0.49 & 76.49 \\
Panel B. Variance & Decomposition (\%) of Off-the-Run Illiquidity & & & & & \\
\hline \multirow{2}{*}{ BOND- } & 2 & 1.61 & 12.57 & 0.46 & 0.35 & 3.86 & 2.45 & 3.93 & 0.05 & 74.68 & 0.00 & 0.04 \\
SHORT & 12 & 6.35 & 20.93 & 1.38 & 3.73 & 2.40 & 5.57 & 8.27 & 0.18 & 49.42 & 0.89 & 0.89 \\
& 24 & 6.30 & 20.76 & 2.95 & 5.74 & 2.02 & 7.84 & 7.26 & 0.18 & 44.29 & 1.35 & 1.31 \\
BOND- & 2 & 0.26 & 0.84 & 0.33 & 0.38 & 0.90 & 0.17 & 0.04 & 0.76 & 0.12 & 96.19 & 0.01 \\
MEDIUM & 12 & 0.50 & 10.13 & 0.95 & 0.34 & 4.12 & 0.59 & 1.39 & 0.77 & 1.06 & 79.89 & 0.26 \\
& 24 & 0.90 & 12.86 & 1.88 & 0.37 & 4.02 & 1.49 & 1.50 & 0.80 & 1.79 & 73.96 & 0.43 \\
BOND- & 2 & 3.39 & 5.12 & 1.31 & 0.13 & 1.35 & 1.01 & 3.89 & 1.71 & 3.51 & 4.91 & 73.67 \\
LONG & 12 & 7.80 & 9.13 & 2.71 & 0.15 & 2.12 & 5.86 & 3.58 & 1.06 & 11.41 & 3.26 & 52.93 \\
& 24 & 8.34 & 13.14 & 3.47 & 0.17 & 2.16 & 7.35 & 3.77 & 0.98 & 14.83 & 2.84 & 42.94 \\
\hline
\end{tabular}

Restricting attention only to off-the-run spreads (Panel B of Table 4), FED explains the most fluctuations in short-term illiquidity $(21 \%)$ compared to other maturities (about 13\% for both medium and long bonds). This is again in agreement with the results from IRFs described previously. Also, while other maturities have little to contribute to the variance of short-term illiquidity, a substantial fraction of variations in long-term illiquidity at the long lag (about 15\%) is explained by short-term illiquidity. All of this evidence supports the hypothesis that shortterm illiquidity captures monetary policy shocks and transfers those shocks into illiquidity of longer maturities. 
In sum, the results are consistent with the notion put forth in Section II that macroeconomic variables affect inventory costs and hence, off-the-run illiquidity. It appears, however, that as argued in Section II, active trading in on-the-run bonds shields market makers from decreases in real wealth and increases in financing costs due to inflation and tighter monetary policy. ${ }^{19}$

\section{E. Impulse Response Functions: Returns}

Figure 4 presents IRFs of bond returns in the VAR system with off-the-run bond illiquidity. Focusing on return forecastability from illiquidity, we find that the illiquidity of off-the-run short-term bonds is useful in forecasting mediumand long-term bond returns. This effect is positive and significant for 2 lags for medium-bond returns and for 3 lags for long-bond returns. ${ }^{20}$ Thus, the contemporaneous effect of short-bond off-the-run illiquidity on medium- and long-term bond returns is negative and significant (Panel B of Table 3), and the lag effect is positive and especially persistent for long-bond returns. These findings are consistent with the Amihud (2002) observation that unexpectedly high illiquidity shock causes future expected returns to rise but contemporaneous prices to fall. Our analysis indicates that the effect of illiquidity on bond returns is more pronounced in the more illiquid longer-term bonds.

From the standpoint of economic significance, we find that a 1-standarddeviation shock to the illiquidity of the off-the run short-term bonds has an annualized impact of 80 basis points (bp) on returns of the medium-term bonds, and $124 \mathrm{bp}$ on returns of the long-term bonds. These are economically significant magnitudes.

The other impulse responses indicate that returns are more strongly affected by macro variables at the short end of the term structure spectrum than at the long end. Thus, active trading in short-term bonds may cause prices in this market to be more responsive to macro innovations. In addition, returns are affected by volatility at medium and long maturities, which is consistent with the traditional risk-return argument.

In unreported results, we find that on-the-run illiquidity has no effect on bond returns. Our results therefore indicate that bond returns contain an illiquidity premium that emanates principally from off-the-run short-term issues. This can be explained as follows: Our findings demonstrate that short-term off-the-run illiquidity absorbs bond market and macroeconomic shocks first and then transmits

\footnotetext{
${ }^{19}$ Although detailed data on bond trading volume is virtually impossible to obtain, some simple statistics on trading volume highlight how different on-the-run issues are from off-the-run Treasuries. According to Sack and Elsasser (2004), the weekly turnover rate for off-the-run Treasury securities in 2003 (that is, weekly trading volume as a percent of outstanding debt) was about $22 \%$, while it was a remarkable $1400 \%$ for on-the-run issues. On-the-run issues accounted for $74 \%$ of the total volume in Treasury coupon securities in 2003.

${ }^{20}$ As indicated in footnote 12, in October 1996, CRSP switched its data source from the Federal Reserve Bank (FRB) to GovPX indicative quotes. To address the issue that the latter quotes are not necessarily firm, we append the FRB illiquidity series with illiquidity obtained from intraday GovPX data as time-weighted average of valid quoted relative spreads (as opposed to indicative quotes from GovPX). In this procedure, while detrending the illiquidity levels we also use a dummy variable for the post-September 1996 period. The main results continue to hold in this robustness check; details are available from the authors.
} 
them into the illiquidity of long-term bonds. In turn, as proposed in Section II, an increase in short-term illiquidity, by portending an increase in illiquidity at other maturities, raises the required return on longer-term bonds. Thus, overall, our results indicate that the liquidity premium in the T-bond market is largely driven by off-the-run illiquidity.

\section{FIGURE 4}

\section{Returns and Off-the-Run Illiquidity}

In Figure 4, we plot impulse response functions of bond returns in the VAR system with off-the-run bond illiquidity. Response to Cholesky 1 standard deviation. Dashed lines represent bootstrap 95\% confidence bands derived via 1,000 bootstrap simulations.

Graph A. Response of Short-Bond Return (RET1) to Endogenous Variables
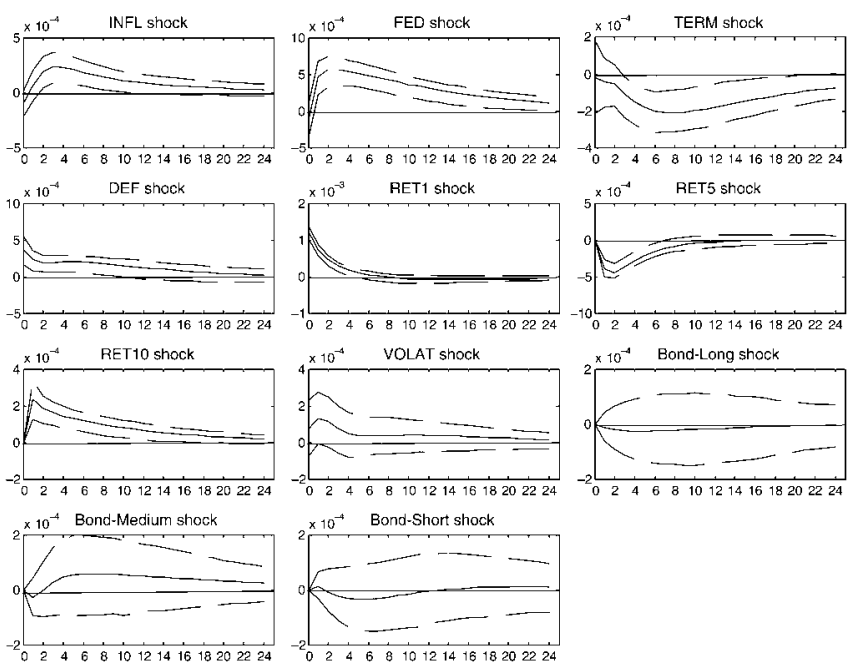

Graph B. Response of Medium-Bond Return (RET5) to Endogenous Variables
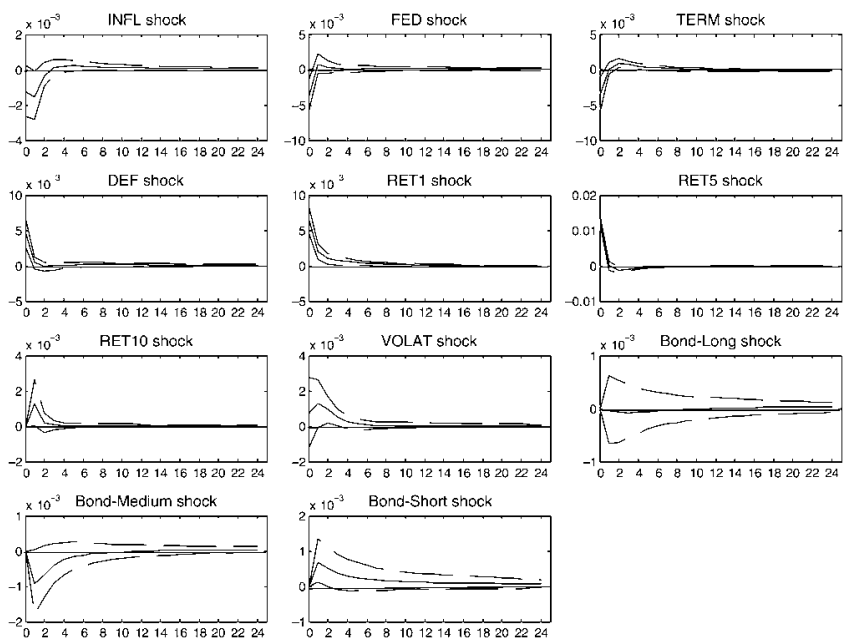
FIGURE 4 (continued)

Returns and Off-the-Run Illiquidity

Graph C. Response of Long-Bond Return (RET10) to Endogenous Variables
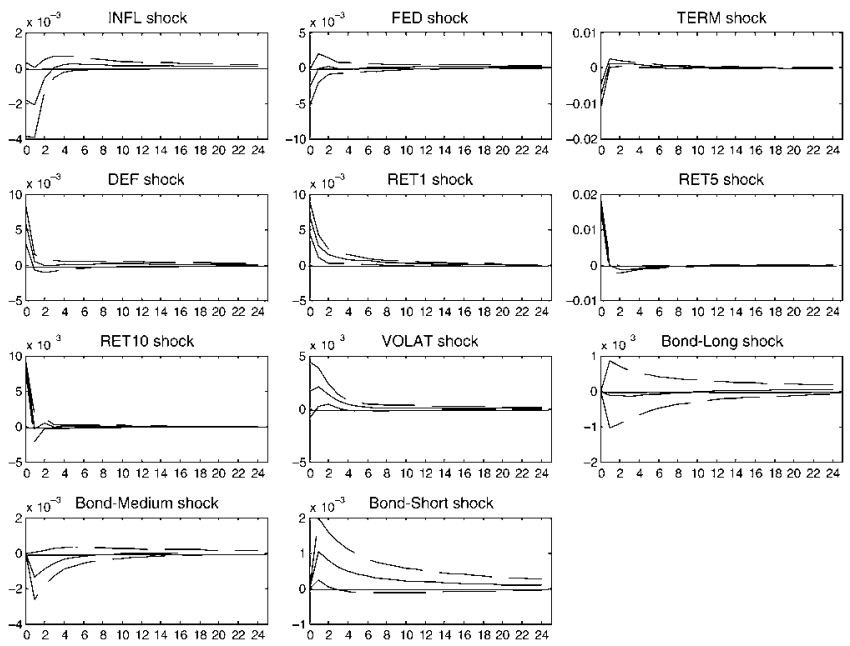

\section{Subperiod Analysis}

Figures 1 and 2 indicate that illiquidity graphs are quite different before and after 1983. In fact, the U.S. economy started emerging from a prolonged recession by the 4th quarter of 1982 . The recovery of the economy was largely attributed to the decline in interest rates due to an altered Federal Reserve policy (Miller, Mitchell, and Hoxworth (1983)). The year 1983 is also characterized by a structural change in government borrowing policy in that the government started focusing more on long bonds after this time. To confirm this, Figure 5 plots the annual relative supply of T-bonds versus T-bills over our sample period. ${ }^{21}$ The outstanding amount of bonds significantly increased in 1983 compared to T-bills, and this pattern dominates the rest of the sample. The evidence on the increasing proportion of long-term debt in total Treasuries outstanding after early 1980s is also reported in Bliss (1996), Gurkaynak, Sack, and Wright (2007), and Garbade (2007). This radical change in supply across maturities could have had an effect

\footnotetext{
${ }^{21}$ The relative supply is calculated as (\$Bills - \$Bonds)/(\$Bills + \$Bonds), where \$Bills and \$Bonds represent the total dollar value of T-bills and T-bonds outstanding as of December of each year. These quantities are obtained from http://www.treasurydirect.gov/govt/reports/pd/mspd/mspd.htm. In part, the focus on long-term bonds arose because in the early 1980s, the Treasury abandoned the so-called "tactical issuance" of bonds under which Treasury officials chose maturities of debt on an offering-by-offering basis. Instead, the Treasury moved to "regular and predictable" schedules of new long-term bond offerings. Mark Stalnecker, Treasury Deputy Assistant Secretary for Federal Finance, justified this by arguing that "regularity of debt management removes a major source of market uncertainty, and assures that Treasury debt can be sold at the lowest possible interest rate consistent with market conditions at the time of sale" (see Garbade (2007)).
} 
on trading activity and hence on illiquidity dynamics. ${ }^{22}$ We therefore split our sample into 2 subperiods, before and after 1983, and repeat the analysis.

\section{FIGURE 5}

Relative Supplies of Treasury Bills and Treasury Bonds (1967-2005)

In Figures 5, \$Bills and \$Bonds, respectively, represent the total dollar values of T-bills and T-bonds outstanding as of December of each year.

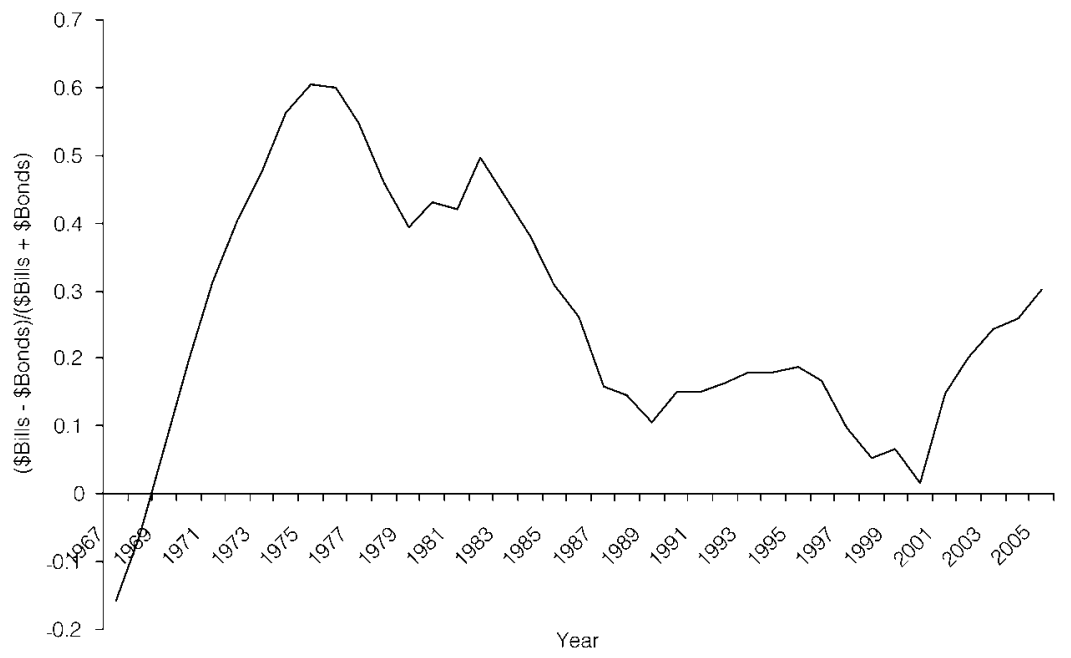

Since the previous analysis indicates that default spread has virtually no effect on our variables of interest and the relevance of default risk is very low for default-free government securities, for parsimony, we do not report or discuss the results for DEF in the subsequent analysis. The results in the 1 st subperiod (1967-1982) are qualitatively similar to the results for the whole sample, and the role of short-term off-the-run illiquidity is even more pronounced for this time period. Given this, instead of presenting a full set of graphs and tables, we summarize the main results for the 1st subperiod. The FED continues to Grangercause short-term off-the-run illiquidity. Short-bond illiquidity Granger-causes the illiquidity series of other off-the-run bonds and not vice versa. Further, the predictive effect of short-term off-the-run illiquidity on the returns of medium- and long-term bonds is positive and significant, as for the whole sample. Overall, monetary shocks seem to be transmitted from the short off-the-run illiquidity into the illiquidity of other maturities and subsequently have a predictive effect for bond returns. The dynamics of the on-the-run illiquidity are also very similar to those for the whole sample. As before, on-the-run illiquidity has no predictability for bond returns, and there are no significant relations (predictability and Granger causality) between illiquidity of different maturities.

\footnotetext{
${ }^{22}$ Fleming and Garbade (2002) suggest that supply may affect the functioning of markets and may impact illiquidity.
} 
The results for the 2nd subperiod (1983-2005) are different from those for the overall sample, and we therefore report and discuss these in some detail. Granger causality results for this subperiod appear in Table 5 for off-the-run illiquidity. As before, bond-short illiquidity causes the illiquidity of medium- and long-term bonds, and the reverse is not true. However, in contrast to the whole sample and the 1st subsample, bond-short has no significant causality effect for bond returns. The causality effect comes from longer-term bonds in this subsample, with both medium- and long-bond illiquidity Granger-causing returns across all maturities.

\title{
TABLE 5
}

Granger Causality Tests: Subperiod Analysis

\begin{abstract}
Table 5 presents $\chi^{2}$ statistics and p-values (in parentheses) of pairwise Granger causality tests between endogenous VAR variables. The null hypothesis is that the row variable does not Granger-cause the column variable. Bond illiquidity estimates are based on proportional quoted spreads across bonds of 3 types of maturities: short (with maturity less than or equal to 1 year), medium (with maturity between 2 and 5 years), and long (with 10 years to maturity). RET1 is the return on a 3-month T-bill, RET5 is the return on 5-year notes, and RET10 is the return on 10-year notes. Bond returns are from CRSP fixed-term indices files. VOLAT is the volatility of returns on a 10 -year note computed as standard deviation of daily returns over each month. TERM is the term premium, defined as the difference between yields on a 10-year T-note and 3-month T-bill. DEF is the default premium, measured as the difference between yields on long-term BAA-rated and AAA-rated bonds (results involving DEF are not reported for brevity). FED is the federal funds rate (indicator of the monetary policy stance). INFL is inflation. The sample is from January 1983 to December 2005 (276 months). Numbers in bold denote significance at the $5 \%$ level.
\end{abstract}

\begin{tabular}{|c|c|c|c|c|c|c|c|}
\hline & \multicolumn{7}{|c|}{ Off-the-Run Illiquidity } \\
\hline & $\begin{array}{l}\text { BOND- } \\
\text { SHORT } \\
\end{array}$ & $\begin{array}{l}\text { BOND- } \\
\text { MEDIUM } \\
\end{array}$ & $\begin{array}{l}\text { BOND- } \\
\text { LONG }\end{array}$ & RET1 & RET5 & RET10 & VOLAT \\
\hline BOND-SHORT & & $\begin{array}{l}11.69 \\
(0.001)\end{array}$ & $\begin{array}{l}5.87 \\
(0.015)\end{array}$ & $\begin{array}{l}0.06 \\
(0.811)\end{array}$ & $\begin{array}{l}0.08 \\
(0.783)\end{array}$ & $\begin{array}{l}0.14 \\
(0.711)\end{array}$ & $\begin{array}{l}0.53 \\
(0.469)\end{array}$ \\
\hline BOND-MEDIUM & $\begin{array}{l}0.84 \\
(0.359)\end{array}$ & & $\begin{array}{l}0.27 \\
(0.606)\end{array}$ & $\begin{array}{l}2.71 \\
(0.099)\end{array}$ & $\begin{array}{l}3.96 \\
(0.047)\end{array}$ & $\begin{array}{l}3.60 \\
(0.058)\end{array}$ & $\begin{array}{l}0.01 \\
(0.927)\end{array}$ \\
\hline BOND-LONG & $\begin{array}{c}1.31 \\
(0.252)\end{array}$ & $\begin{array}{l}0.09 \\
(0.764)\end{array}$ & & $\begin{array}{l}4.66 \\
(0.031)\end{array}$ & $\begin{array}{l}5.04 \\
(0.025)\end{array}$ & $\begin{array}{l}4.97 \\
(0.026)\end{array}$ & $\begin{array}{c}0.06 \\
(0.807)\end{array}$ \\
\hline RET1 & $\begin{array}{l}0.22 \\
(0.640)\end{array}$ & $\begin{array}{c}0.27 \\
(0.60)\end{array}$ & $\begin{array}{l}2.16 \\
(0.142)\end{array}$ & & $\begin{array}{l}7.89 \\
(0.005)\end{array}$ & $\begin{array}{l}4.34 \\
(0.037)\end{array}$ & $\begin{array}{l}1.81 \\
(0.179)\end{array}$ \\
\hline RET5 & $\begin{array}{l}0.67 \\
(0.412)\end{array}$ & $\begin{array}{c}1.91 \\
(0.167)\end{array}$ & $\begin{array}{l}2.82 \\
(0.091)\end{array}$ & $\begin{array}{l}13.40 \\
(0.00)\end{array}$ & & $\begin{array}{l}0.00 \\
(0.985)\end{array}$ & $\begin{array}{c}0.15 \\
(0.694)\end{array}$ \\
\hline RET10 & $\begin{array}{c}0.05 \\
(0.821)\end{array}$ & $\begin{array}{l}2.08 \\
(0.149)\end{array}$ & $\begin{array}{l}2.89 \\
(0.089)\end{array}$ & $\begin{array}{l}5.27 \\
(0.022)\end{array}$ & $\begin{array}{l}0.10 \\
(0.754)\end{array}$ & & $\begin{array}{l}0.13 \\
(0.717)\end{array}$ \\
\hline VOLAT & $\begin{array}{l}0.50 \\
(0.480)\end{array}$ & $\begin{array}{l}0.44 \\
(0.509)\end{array}$ & $\begin{array}{l}1.98 \\
(0.159)\end{array}$ & $\begin{array}{l}12.20 \\
(0.001)\end{array}$ & $\begin{array}{l}0.20 \\
(0.654)\end{array}$ & $\begin{array}{l}0.34 \\
(0.558)\end{array}$ & \\
\hline TERM & $\begin{array}{l}0.76 \\
(0.384)\end{array}$ & $\begin{array}{l}0.86 \\
(0.353)\end{array}$ & $\begin{array}{c}1.55 \\
(0.213)\end{array}$ & $\begin{array}{c}1.10 \\
(0.29)\end{array}$ & $\begin{array}{l}5.61 \\
(0.018)\end{array}$ & $\begin{array}{l}6.33 \\
(0.012)\end{array}$ & $\begin{array}{l}0.21 \\
(0.644)\end{array}$ \\
\hline FED & $\begin{array}{l}1.88 \\
(0.170)\end{array}$ & $\begin{array}{l}2.12 \\
(0.146)\end{array}$ & $\begin{array}{l}4.08 \\
(0.044)\end{array}$ & $\begin{array}{l}31.82 \\
(0.00)\end{array}$ & $\begin{array}{l}0.51 \\
(0.474)\end{array}$ & $\begin{array}{l}0.86 \\
(0.355)\end{array}$ & $\begin{array}{c}0.02 \\
(0.897)\end{array}$ \\
\hline INFL & $\begin{array}{l}0.03 \\
(0.857)\end{array}$ & $\begin{array}{l}1.87 \\
(0.171)\end{array}$ & $\begin{array}{c}0.005 \\
(0.942)\end{array}$ & $\begin{array}{l}1.08 \\
(0.298)\end{array}$ & $\begin{array}{l}3.11 \\
(0.078)\end{array}$ & $\begin{array}{l}3.62 \\
(0.057)\end{array}$ & $\begin{array}{c}0.60 \\
(0.441)\end{array}$ \\
\hline
\end{tabular}

There is also a different monetary policy effect on bond illiquidity. While for the whole period FED has a causality effect on the illiquidity of both shortand medium-term bonds (Panel $\mathrm{C}$ of Table 2), FED only Granger-causes bondlong illiquidity in the later subsample. These causality results present a first indication that the informational role of short-term illiquidity has now been passed 
on to long-term illiquidity. The causality results for on-the-run illiquidity are all insignificant. $^{23}$

The variance decomposition results are reported in Table 6 for on-the-run (Panel A) and off-the-run (Panel B) illiquidity. The comparison of the on-therun with the off-the-run decomposition leads to the same conclusions as for the full sample. Thus, monetary policy (FED) explains a considerably higher fraction of variance for off-the-run illiquidity than for on-the-run illiquidity. This holds across different maturities. Thus, for example, for long bonds at long lags, FED explains about $12 \%-13 \%$ of variation for off-the-run illiquidity versus about $0.4 \%$ for the on-the-run counterpart. Similar relations are observed in the full sample, and they support our finding of the differences between on-the-run and off-the-run illiquidity.

\title{
TABLE 6
}

Variance Decomposition of Bond Illiquidity: Subperiod Analysis

\begin{abstract}
Table 6 presents the variance decompositions computed from a VAR with endogenous variables INFL, FED, TERM, DEF, VOLAT, RET1, RET5, RET10, BOND-SHORT, BOND-MEDIUM, and BOND-LONG. It is estimated with 1 lag and a constant term. Bond illiquidity estimates are based on proportional quoted spreads across bonds of 3 types of maturities: short (with maturity less than or equal to 1 year), medium (with maturity between 2 and 5 years), and long (with 10 years to maturity). RET1 is the return on a 3-month T-bill, RET5 is the return on 5-year notes, and RET10 is the return on 10-year notes. Bond returns are from CRSP fixed-term indices files. VOLAT is the volatility of returns on a 10-year note computed as standard deviation of daily returns over each month. TERM is the term premium, defined as the difference between yields on a 10-year T-note and 3-month T-bill. DEF is the default premium, measured as the difference between yields on long-term BAA-rated and AAA-rated bonds (results involving DEF are not reported for brevity). FED is the federal funds rate (indicator of the monetary policy stance). INFL is inflation. The sample is from January 1983 to December 2005 (276 months).
\end{abstract}

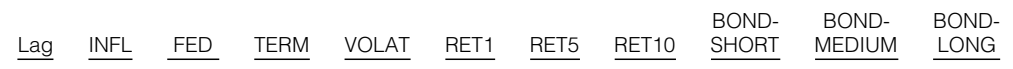

Panel A. Variance Decomposition (\%) of On-the-Run Illiquidity

\begin{tabular}{lrllllllllrr} 
BOND- & 2 & 0.79 & 0.02 & 2.85 & 0.10 & 0.49 & 0.31 & 0.55 & 90.08 & 2.62 & 0.00 \\
SHORT & 12 & 0.57 & 0.11 & 4.02 & 0.93 & 0.71 & 0.23 & 1.00 & 66.27 & 17.83 & 1.16 \\
& 24 & 0.55 & 0.13 & 3.76 & 1.07 & 1.24 & 0.25 & 0.99 & 62.05 & 18.51 & 1.26 \\
BOND- & 2 & 0.20 & 0.55 & 1.24 & 1.00 & 1.43 & 0.19 & 1.55 & 2.42 & 89.67 & 1.48 \\
MEDIUM & 12 & 0.14 & 0.66 & 1.68 & 1.46 & 4.30 & 0.29 & 1.76 & 4.78 & 77.18 & 4.49 \\
& 24 & 0.17 & 1.02 & 1.64 & 1.38 & 5.22 & 0.51 & 1.67 & 5.09 & 73.56 & 4.30 \\
BOND- & 2 & 0.20 & 0.22 & 0.12 & 1.19 & 0.21 & 0.41 & 2.04 & 0.43 & 12.20 & 82.93 \\
LONG & 12 & 0.22 & 0.40 & 0.62 & 1.29 & 1.47 & 0.66 & 2.38 & 0.44 & 16.36 & 75.96 \\
& 24 & 0.22 & 0.39 & 0.88 & 1.27 & 1.91 & 0.82 & 2.35 & 0.47 & 16.31 & 74.68 \\
Panel B. Variance Decomposition (\%) of Off-the-Run Illiquidity & & & & \\
\hline \multirow{2}{*}{ BOND- } & 2 & 1.65 & 0.37 & 3.12 & 8.27 & 0.73 & 1.03 & 1.21 & 80.65 & 0.11 & 0.07 \\
SHORT & 12 & 0.94 & 1.04 & 5.01 & 5.15 & 0.43 & 0.54 & 2.18 & 70.16 & 4.93 & 0.37 \\
& 24 & 0.79 & 0.89 & 4.51 & 4.49 & 0.99 & 0.58 & 2.39 & 63.67 & 7.52 & 0.39 \\
BOND- & 2 & 0.44 & 0.33 & 0.05 & 0.51 & 0.03 & 1.14 & 4.89 & 3.25 & 89.34 & 0.00 \\
MEDIUM & 12 & 1.35 & 1.20 & 0.05 & 1.03 & 1.11 & 0.97 & 7.09 & 5.46 & 79.38 & 0.08 \\
& 24 & 1.13 & 1.01 & 0.06 & 1.27 & 2.51 & 1.32 & 6.59 & 9.34 & 69.28 & 0.16 \\
BOND- & 2 & 0.20 & 2.18 & 0.31 & 3.07 & 0.05 & 0.72 & 1.51 & 0.65 & 18.45 & 72.34 \\
LONG & 12 & 0.17 & 11.75 & 0.35 & 3.67 & 0.17 & 0.33 & 3.79 & 2.73 & 21.81 & 54.56 \\
& 24 & 0.26 & 13.37 & 0.76 & 3.11 & 0.20 & 0.30 & 4.44 & 5.27 & 23.27 & 46.10 \\
\hline
\end{tabular}

Moving to a comparison across bonds within each seasonedness category (on- and off-the-run), we find that for on-the-run illiquidity, the variance decomposition in the 2nd subsample is qualitatively similar to the whole sample results and indicates almost no relation between monetary policy and illiquidity.

${ }^{23}$ These results are not reported for brevity but are available from the authors. 
The results for off-the-run illiquidity, however, are different. From Panel B of Table 4, we observe that for the whole sample, FED explains between $13 \%$ and $21 \%$ of the short-bond variance and between $5 \%$ and $13 \%$ of the long-bond variance. These figures change for the 2nd subsample, where at long lags, FED explains only $1 \%$ of the variance of short-bond off-the-run illiquidity, but about $13 \%$ of the variation in long-bond illiquidity. Overall, for the full sample, FED has stronger explanatory power for short-bond than for long-bond illiquidity, while in the 2nd subsample, FED explains more variation in long-bond rather than shortbond illiquidity. All of this evidence thus helps us understand how the informational role of short-term illiquidity has been passed on to the long-term illiquidity in the 2nd subsample.

Figure 6 presents IRFs for bond returns and demonstrates that bond-long illiquidity has a significant positive and quite persistent effect on medium- and long-term bond returns. The effect persists for longer lags compared to the whole sample. It is also economically significant. A one-standard-deviation shock of the illiquidity of off-the-run long-term bonds has an annualized impact of $108 \mathrm{bp}$ and $171 \mathrm{bp}$ on medium- and long-term bond returns, respectively.

The IRFs for off-the-run illiquidity as the dependent variable are not reported for brevity and can be summarized as follows: The only significant cross-illiquidity effect is the predictive effect of medium illiquidity on long illiquidity. Consistent with the Granger causality results and in contrast to the whole sample evidence, FED only has a significant positive impact on the illiquidity of

FIGURE 6

Returns and Off-the-Run Illiquidity: Subperiod Analysis (1983-2005)

In Figure 6, we plot impulse response functions for bond returns in the VAR system with off-the-run bond illiquidity. Response to Cholesky 1 standard deviation. Dashed lines represent bootstrap 95\% confidence bands derived via 1,000 bootstrap simulations.

Graph A. Response of Short-Bond Return (RET1) to Endogenous Variables
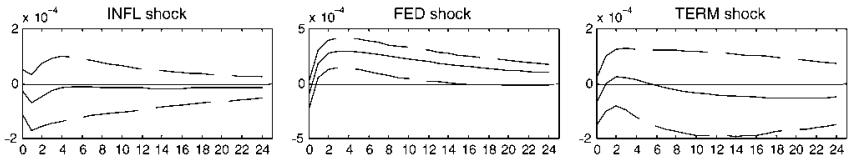

$\times 10^{-4} \quad$ RET1 shock
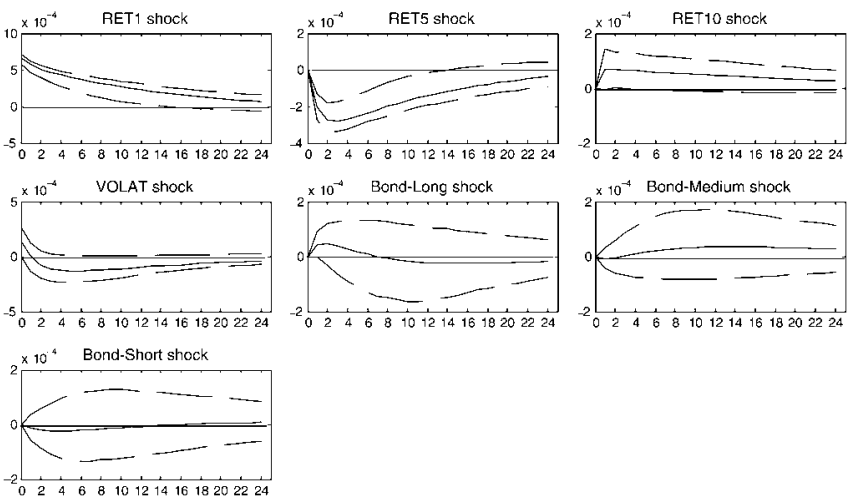
FIGURE 6 (continued)

Returns and Off-the-Run Illiquidity: Subperiod Analysis (1983-2005)

Graph B. Response of Medium-Bond Return (RET5) to Endogenous Variables
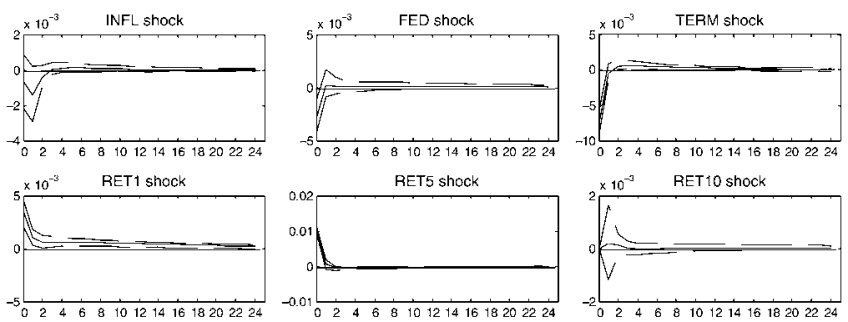

RET5 shock
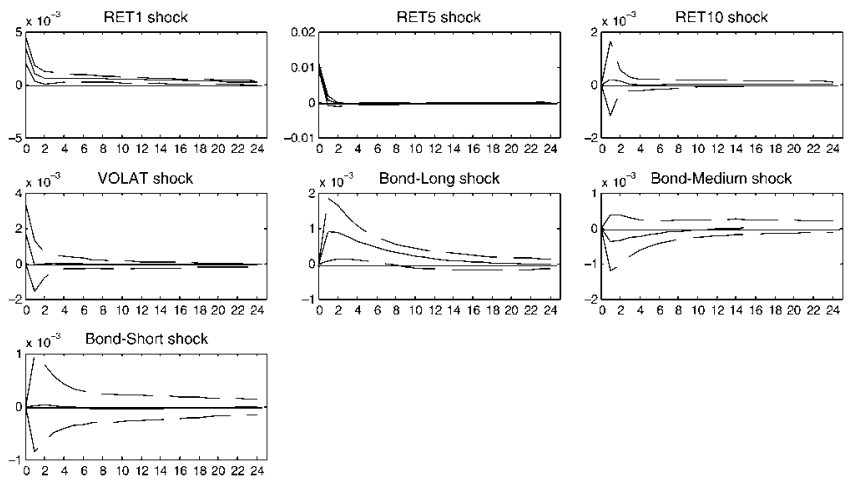

Graph C. Response of Long-Bond Return (RET10) to Endogenous Variables
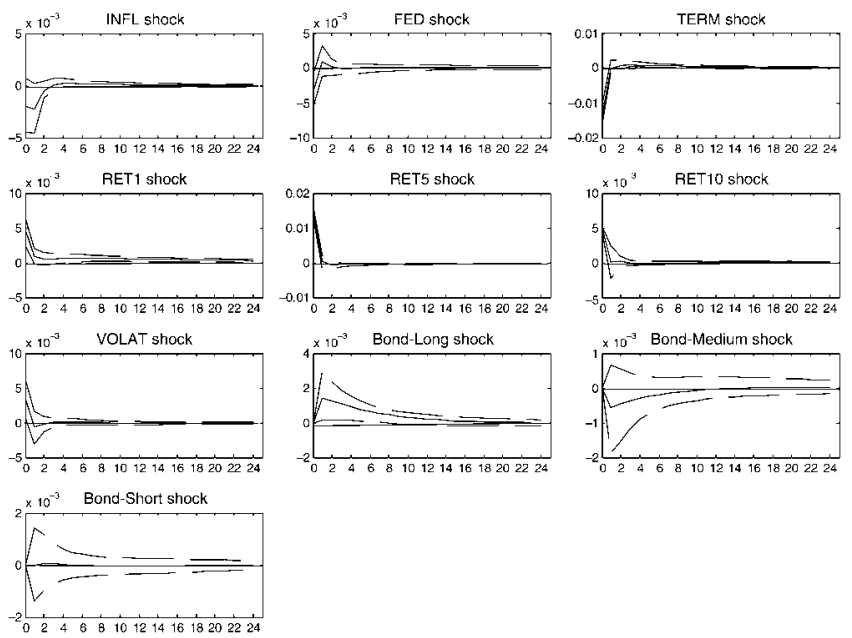

long-term bonds. Therefore, it is the illiquidity of long-term bonds that picks up monetary policy contractions and transfers them into bond returns. ${ }^{24}$

In sum, we conclude that both for the overall sample and for the subperiods, illiquidity shocks are picked up by the off-the-run bonds and transmitted to the rest of the bond market. For the full sample, the transmission occurs through

\footnotetext{
${ }^{24}$ To address this hypothesis, we run the following experiment: We restrict the VAR such that the interaction coefficients between FED and off-the-run BOND-LONG are set to zero. We therefore terminate any information linkage from FED to BOND-LONG and vice versa. As a result, we find that the predictive effect of BOND-LONG for bond returns disappears. This confirms our proposition that monetary policy affects returns via off-the-run illiquidity.
} 
short-run bonds. Consistent with the increasing role of the long-term bond in the 2nd half of the sample, however, long-maturity bonds play a more critical role in the transmission in the latter subperiod.

\section{Conclusion}

U.S. Treasury markets are critical for asset allocation purposes and also provide indicators for benchmark riskless rates in the economy. Since bond illiquidity influences the efficacy of asset allocation and impacts interest rate discovery, it is important to understand the dynamics of bond market trading costs. Using extensive time series that span over 35 years, we analyze Treasury market illiquidity across maturities and seasonedness. Our aims are to explore whether illiquidities across these attributes are differentially affected by macroeconomic conditions, and to understand variations in the illiquidity premium across bonds.

We find that illiquidity increases in recessions across all maturities. However, the increase is especially pronounced for short-term bonds. The difference between spreads of long- and short-term bonds also increases during recessions for both on-the-run and off-the-run issues. The evidence suggests that investors may shift into short-term bonds during recessions and invest in both on-the-run and off-the-run bonds.

Our results are consistent with the notion that the effect of macro variables on dealer costs is most relevant in the less liquid off-the-run sector. On-the-run illiquidity across all maturities is materially affected only by volatility. However, off-the-run illiquidity is driven by inflation, monetary policy surprises, bond returns, and volatility. Overall, off-the-run illiquidity is affected by a larger set of economic variables than its on-the-run counterpart.

We also explore pricing implications of on-the-run and off-the-run illiquidity of different maturities. We find that for the overall sample, short-term off-the-run illiquidity forecasts returns across all maturities, but that the return forecasting ability of on-the-run illiquidity is limited. Similar to the effect of stock illiquidity on stock returns (Amihud (2002)), short-term off-the-run illiquidity has a negative contemporaneous impact on bond returns and a positive lag effect. The lag effect persists longer for more illiquid bonds. Consistent with the increasing role of the long bond in the Fed's policy during recent years, the illiquidity premium emanates from long-term off-the-run illiquidity in the 2 nd half of the sample. Our results indicate that off-the-run illiquidity is the primary source of return forecastability (and thus, the liquidity premium) in the Treasury market.

\section{Appendix. The Vector Autoregressive System}

We use the following VAR specification:

$$
\begin{aligned}
X_{t} & =\sum_{j=1}^{K} a_{1 j} X_{t-j}+\sum_{j=1}^{K} b_{1 j} Y_{t-j}+\sum_{j=1}^{K} c_{1 j} Z_{t-j}+u_{t}, \\
Y_{t} & =\sum_{j=1}^{K} a_{2 j} X_{t-j}+\sum_{j=1}^{K} b_{2 j} Y_{t-j}+\sum_{j=1}^{K} c_{2 j} Z_{t-j}+v_{t},
\end{aligned}
$$




$$
Z_{t}=\sum_{j=1}^{K} a_{3 j} X_{t-j}+\sum_{j=1}^{K} b_{3 j} Y_{t-j}+\sum_{j=1}^{K} c_{3 j} Z_{t-j}+\varepsilon_{t}
$$

In the above system, $X$ (BOND-SHORT, BOND-MEDIUM, BOND-LONG) is a vector that represents the illiquidity of short-, medium-, and long-term bonds, respectively. Further, $Y$ (RET1, RET5, RET10, VOLAT) is a vector of returns and volatility, where RET1, RET5, and RET10 represent returns on short-, medium-, and long-term bonds, respectively, and VOLAT denotes the volatility of the 10-year T-note. Finally, Z(INFL, FED, TERM, DEF) is a vector of macroeconomic variables that comprises inflation, the FED, the term spread, and the default spread.

We run 2 VAR specifications for on-the-run and off-the-run illiquidity. Therefore, vector $X$ is either the on-the-run or the off-the-run illiquidity series. However, vectors $Y$ and $Z$ are the same in all VAR specifications. The number of lags, $K$, in the VAR is chosen based on the AIC and BIC (for parsimony, the minimum lag suggested by the 2 criteria is used).

\section{References}

Acharya, V. V., and L. H. Pedersen. "Asset Pricing with Liquidity Risk." Journal of Financial Economics, 77 (2005), 375-410.

Amihud, Y. "Illiquidity and Stock Returns: Cross-Section and Time-Series Effects." Journal of Financial Markets, 5 (2002), 31-56.

Amihud, Y., and H. Mendelson. "Asset Pricing and the Bid-Ask Spread." Journal of Financial Economics, 17 (1986), 223-249.

Amihud, Y., and H. Mendelson. "The Effect of Beta, Bid-Ask Spread, Residual Risk, and Size on Stock Returns." Journal of Finance, 44 (1989), 479-486.

Amihud, Y., and H. Mendelson. "Liquidity, Maturity, and the Yields on U.S. Treasury Securities." Journal of Finance, 46 (1991), 1411-1425.

Amihud, Y.; H. Mendelson; and L. Pedersen. "Liquidity and Asset Prices." Foundations and Trends in Finance, 1 (2005), 269-364.

Ang, A., and M. Piazzesi. "A No-Arbitrage Vector Autoregression of Term Structure Dynamics with Macroeconomic and Latent Variables." Journal of Monetary Economics, 50 (2003), 745-787.

Balduzzi, P.; E. J. Elton; and T. C. Green. "Economic News and Bond Prices: Evidence from the U.S. Treasury Market." Journal of Financial and Quantitative Analysis, 36 (2001), 523-543.

Beber, A.; M. W. Brandt; and K. A. Kavajecz. "Flight-to-Quality or Flight-to-Liquidity? Evidence from the Euro-Area Bond Market." Review of Financial Studies, 22 (2009), 925-957.

Benston, G. J., and R. L. Hagerman. "Determinants of Bid-Asked Spreads in the Over-the-Counter Market." Journal of Financial Economics, 1 (1974), 353-364.

Bliss, R. "Testing Term Structure Estimation Methods.” Advances in Futures and Options Research, 9 (1996), 197-231.

Boudoukh, J., and R. F. Whitelaw. "Liquidity as a Choice Variable: A Lesson from the Japanese Government Bond Market." Review of Financial Studies, 6 (1993), 265-292.

Brandt, M. W., and K. A. Kavajecz. "Price Discovery in the U.S. Treasury Market: The Impact of Order Flow and Liquidity on the Yield Curve." Journal of Finance, 59 (2004), 2623-2654.

Brennan, M. J., and A. Subrahmanyam. "Market Microstructure and Asset Pricing: On the Compensation for Illiquidity in Stock Returns." Journal of Financial Economics, 41 (1996), 441-464.

Brunnermeier, M. K., and L. H. Pedersen. "Market Liquidity and Funding Liquidity." Review of Financial Studies, 22 (2009), 2201-2238.

Campbell, J. Y., and J. Ammer. "What Moves Stock and Bond Markets? A Variance Decomposition for Long-Term Asset Returns." Journal of Finance, 48 (1993), 3-37.

Chordia, T.; R. Roll; and A. Subrahmanyam. "Market Liquidity and Trading Activity." Journal of Finance, 56 (2001), 501-530.

Chordia, T.; A. Sarkar; and A. Subrahmanyam. "Common Determinants of Bond and Stock Market Liquidity: The Impact of Financial Crises, Monetary Policy, and Mutual Fund Flows." Working Paper, University of California at Los Angeles (2002).

Chordia, T.; A. Sarkar; and A. Subrahmanyam. "An Empirical Analysis of Stock and Bond Market Liquidity." Review of Financial Studies, 18 (2005), 85-129.

Duffie, D.; N. Gârleanu; and L. H. Pedersen. "Valuation in Over-the-Counter Markets." Review of Financial Studies, 20 (2007), 1865-1900. 
Dumas, B. "A Test of the International CAPM Using Business Cycles Indicators as Instrumental Variables.” In The Internationalization of Equity Markets, J. A. Frankel, ed. Chicago, IL: University of Chicago Press (1994)

Fama, E. F., and K. R. French. "Common Risk Factors in the Returns on Stocks and Bonds." Journal of Financial Economics, 33 (1993), 3-56.

Fleming, M. "Measuring Treasury Market Liquidity." Federal Reserve Bank of New York Economic Policy Review, 9 (2003), 83-108.

Fleming, M. J., and K. D. Garbade. "When the Back Office Moved to the Front Burner: Settlement Fails in the Treasury Market After 9/11." Economic Policy Review, 8 (2002), 35-57.

Fleming, M. J., and E. M. Remolona. "What Moves the Bond Market?" Economic Policy Review, 3 (1997), 31-50.

Fleming, M. J., and E. M. Remolona. "Price Formation and Liquidity in the U.S. Treasury Market: The Response to Public Information." Journal of Finance, 54 (1999), 1901-1915.

Garbade, K. D. "The Emergence of 'Regular and Predictable' as a Treasury Debt Management Strategy.” Economic Policy Review, 13 (2007), 53-71.

Goldreich, D.; B. Hanke; and P. Nath. "The Price of Future Liquidity: Time-Varying Liquidity in the U.S. Treasury Market." Review of Finance, 9 (2005), 1-32.

Goyenko, R. Y., and A. D. Ukhov. "Stock and Bond Market Liquidity: A Long-Run Empirical Analysis.” Journal of Financial and Quantitative Analysis, 44 (2009), 189-212.

Green, T. C. "Economic News and the Impact of Trading on Bond Prices." Journal of Finance, 59 (2004), 1201-1233.

Gurkaynak, R. S.; B. Sack; and J. H. Wright. "The U.S. Treasury Yield Curve: 1961 to the Present." Journal of Monetary Economics, 54 (2007), 2291-2304.

Ho, T. S. Y., and H. R. Stoll. "The Dynamics of Dealer Markets under Competition.” Journal of Finance, 38 (1983), 1053-1074.

Huang, R. D.; J. Cai; and X. Wang. "Information-Based Trading in the Treasury Note Inter-Dealer Broker Market.” Journal of Financial Intermediation, 11 (2002), 269-296.

Jones, C. M. "A Century of Stock Market Liquidity and Trading Costs." Working Paper, Columbia University (2002).

Kamara, A. "Liquidity, Taxes, and Short-Term Treasury Yields." Journal of Financial and Quantitative Analysis, 29 (1994), 403-417.

Krishnamurthy, A. "The Bond/Old-Bond Spread." Journal of Financial Economics, 66 (2002), 463-506.

Longstaff, F. A. "The Flight-to-Liquidity Premium in U.S. Treasury Bond Prices.” Journal of Business, 77 (2004), 511-526.

Merton, R. C. "Optimal Consumption and Portfolio Rules in a Continuous-Time Model." Journal of Economic Theory, 3 (1971), 373-413.

Miller, G. H. Jr.; K. Mitchell; and D. Hoxworth. "The U.S. Economy and Monetary Policy in 1983." Economic Review, Federal Reserve Bank of Kansas City, December (1983), 3-21.

O'Hara, M., and G. S. Oldfield. "The Microeconomics of Market Making." Journal of Financial and Quantitative Analysis, 21 (1986), 361-376.

Pastor, L., and R. F. Stambaugh. "Liquidity Risk and Expected Stock Returns.” Journal of Political Economy, 111 (2003), 642-685.

Sack, B., and R. Elsasser. "Treasury Inflation-Indexed Debt: A Review of the U.S. Experience." Economic Policy Review, 10 (2004), 47-63.

Shiller, R. J. Market Volatility. Cambridge, MA: MIT Press (1989).

Shiller, R. J., and P. Perron. "Testing the Random Walk Hypothesis: Power vs. Frequency of Observation." Economics Letters, 18 (1985), 381-386.

Thorbecke, W. "On Stock Market Returns and Monetary Policy.” Journal of Finance, 52 (1997), $635-654$.

Warga, A. "Bond Returns, Liquidity, and Missing Data." Journal of Financial and Quantitative Analysis, 27 (1992), 605-617. 